\title{
Construction of Donor-Acceptor Polymers via Cyclopentannulation of Poly(arylene ethynylene)s
}

\author{
Xinju Zhu ${ }^{\star}$ Sambasiva R. Bheemireddy, ${ }^{\star}$ Somisetti V. Sambasivarao ${ }^{\dagger}$ Peter W. Rose, \\ Rubicelys Torres Guzman, ${ }^{\dagger}$ Amanda G. Waltner, ${ }^{\dagger}$ Kateri H. DuBay ${ }^{\dagger *}$ and Kyle N. Plunkett ${ }^{\ddagger *}$ \\ Department of Chemistry and Biochemistry and the Materials Technology Center, Southern Illinois \\ University, Carbondale, IL 62901 United States \\ 'Department of Chemistry, University of Virginia, Charlottesville, VA 22904 United States \\ kplunkett@chem.siu.edu; dubay@virginia.edu
}

CONTENTS:

1) Synthesis of bromo- and alkynyl-containing arylene monomers

2) Polymer samples under normal and UV-light

3) Dynamic light scattering histograms

4) Experimental procedures

5) ${ }^{1} \mathrm{H}$ and ${ }^{13} \mathrm{C}$ NMR spectra for compounds

6) References
PAGE

SI2

SI3

SI4

SI5-SI1 1

SI12-SI28

SI29 

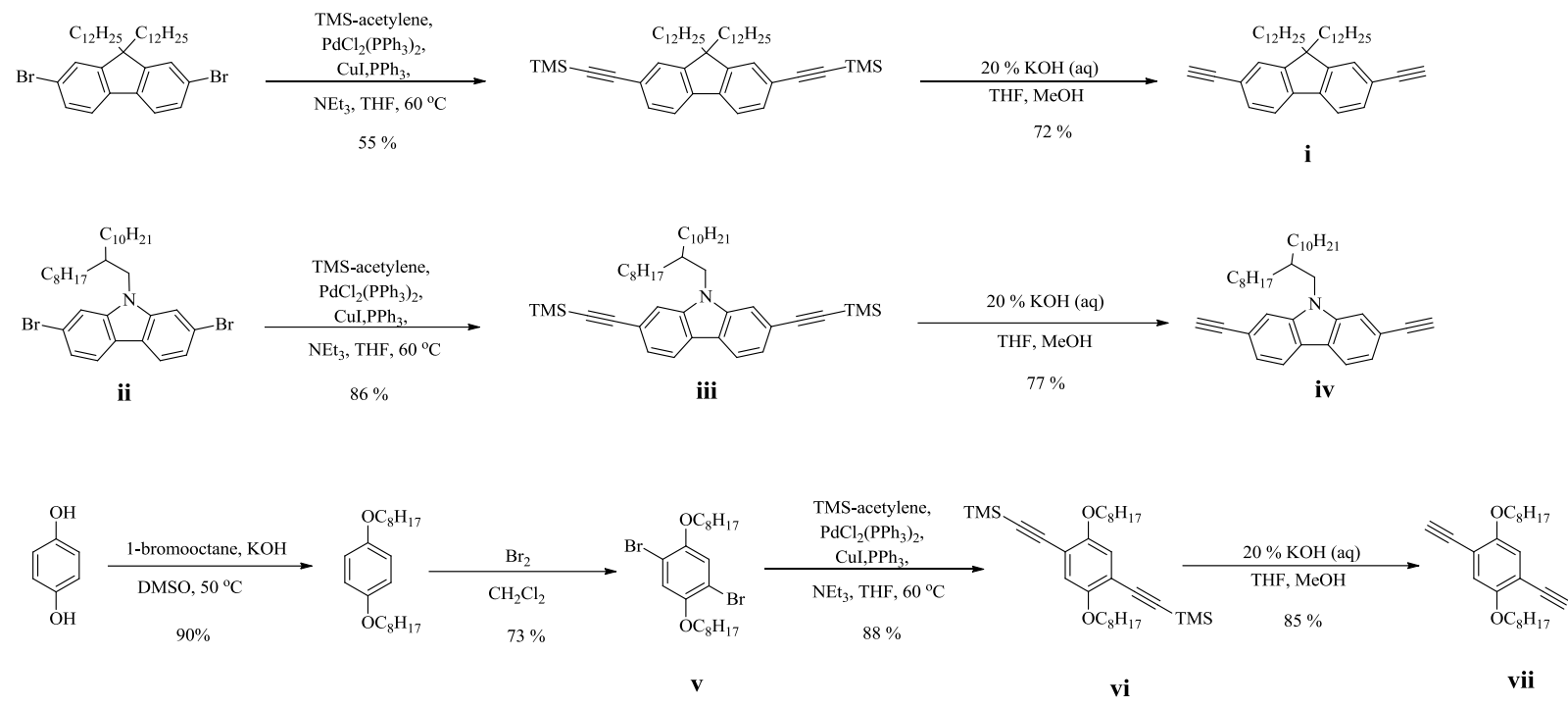

Scheme SI1 Synthesis of bromo- and alkynyl-containing arylene monomers. 


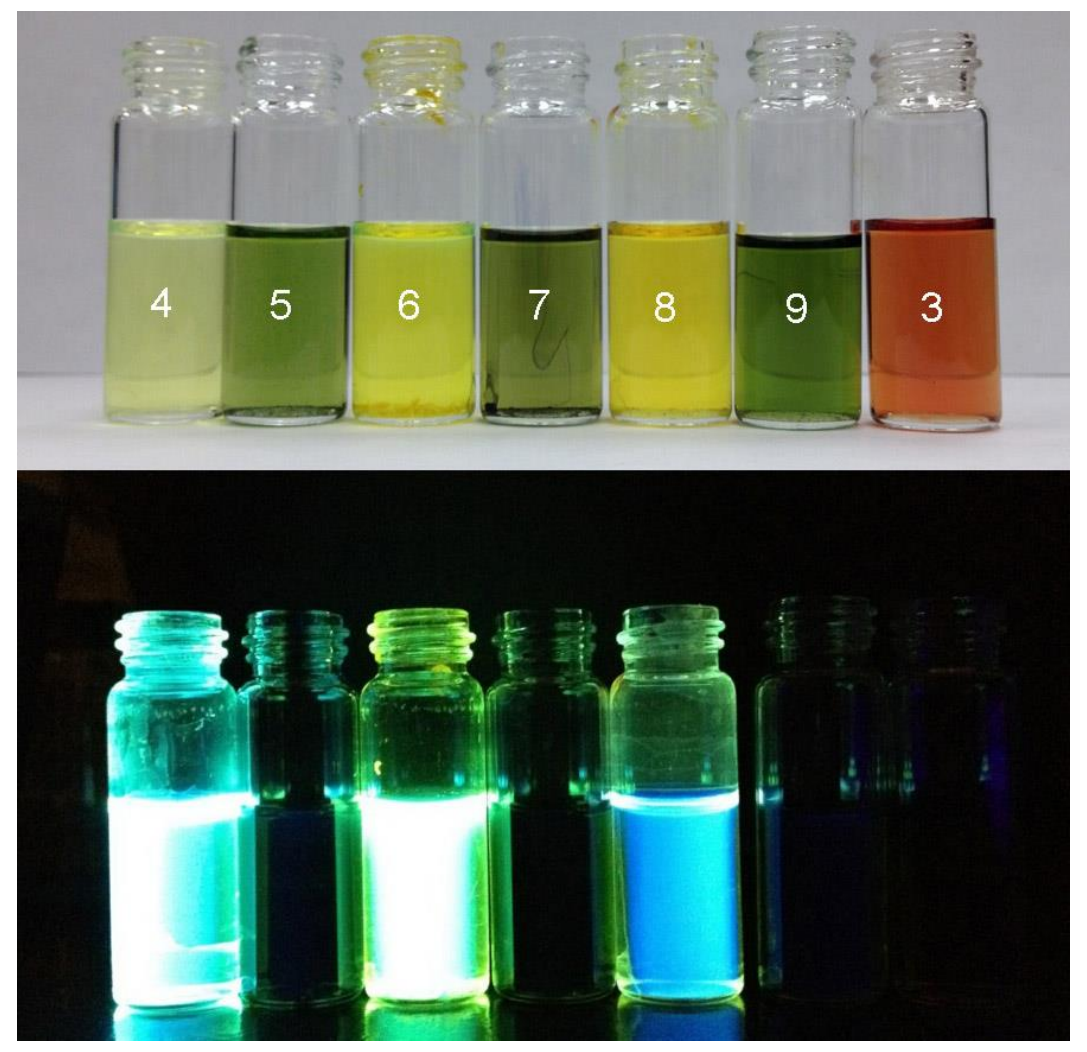

Figure SI1. Solutions of polymers 4-9 and modifier 3 under normal (top) and UV (bottom) light. CP-PAH containing polymers are not fluorescent. 


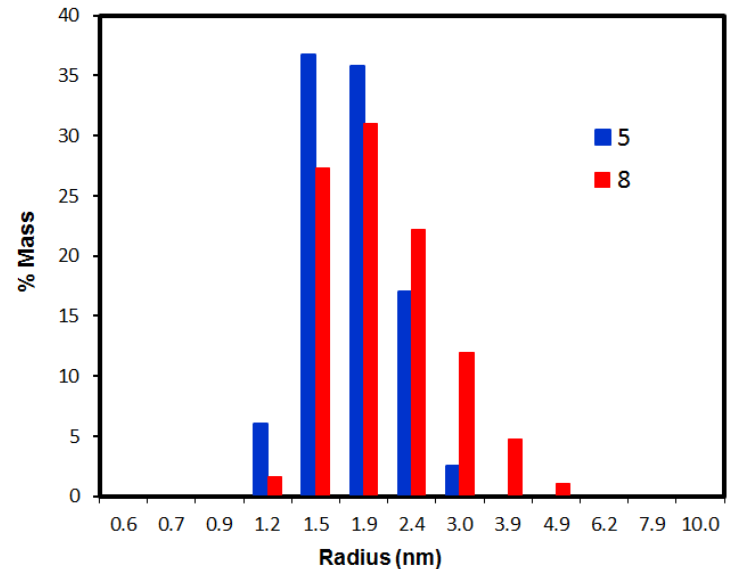

Figure SI2. Dynamic light scattering histograms of 5 and 8.

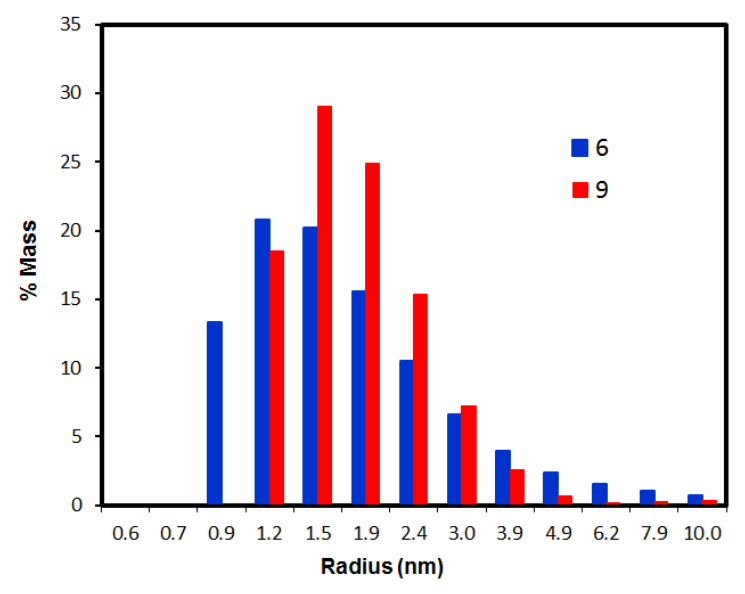

Figure SI3. Dynamic light scattering histograms of 6 and 9. 


\section{Experimental procedures}

Unless otherwise noted, all reagents were used as received and all reactions were carried out under an argon atmosphere. Column chromatography was performed on a CombiFlash ${ }^{\circledR} \mathrm{Rf}$ system with Redisep normal phase silica columns (Teledyne ISCO Inc., Lincoln, NE). $\quad{ }^{1} \mathrm{H}$ NMR and ${ }^{13} \mathrm{C}$ NMR were recorded on a Varian 400 MHz NMR station at room temperature, unless otherwise noted. Millipore filtrations were accomplished with a $47 \mathrm{~mm}$ Millipore vacuum filter (PTFE or Nylon). Polymer molecular weights were determined versus polystyrene standards using an Waters 2690 seperations module, Waters 2410 refractive index detector, Waters 996 photodiode array detector and varian GPC/SEC columns. Cyclic voltammetry was performed on a CHInstruments $700 \mathrm{D}$ potentiostat with a $0.1 \mathrm{M}$ tetrabutylammonium hexafluorophosphate solution (THF) using a glassy carbon electrode, platinum counter electrode, and a $\mathrm{Ag} / \mathrm{AgCl}$ reference electrode. High resolution mass spectra were obtained from the University of Illinois Mass Spectrometry Services.

1,2-di-p-tolylethyne. ${ }^{1}$ In a glovebox were combined 4-bromotoluene (10.0 g, $\left.58.5 \mathrm{mmol}\right)$, CuI (1.11 g, 5.85 $\mathrm{mmol}), \mathrm{PdCl}_{2}\left(\mathrm{PPh}_{3}\right)_{2}(2.10 \mathrm{~g}, 2.93 \mathrm{mmol})$ and toluene $(50 \mathrm{~mL})$ in a $250 \mathrm{~mL}$ round bottom flask. The flask was capped with a septum and electrical tape and taken out of glovebox. Degassed DBU (52 mL, $350 \mathrm{mmol}), \mathrm{H}_{2} \mathrm{O}$ $(0.53 \mathrm{~mL})$, and TMS-acetylene $(2.90 \mathrm{~g}, 29.3 \mathrm{mmol})$ were subsequently added under Ar. The reaction mixture was stirred at $60{ }^{\circ} \mathrm{C}$ overnight and then cooled to room temperature. $\mathrm{CH}_{2} \mathrm{Cl}_{2}(200 \mathrm{~mL})$ was added and the mixture was extracted with $1 \mathrm{M} \mathrm{HCl}(2 \mathrm{X} 100 \mathrm{~mL})$, water $(2 \mathrm{X} 100 \mathrm{~mL})$ and brine $(100 \mathrm{~mL})$. The organic layer was dried over $\mathrm{MgSO}_{4}$ and concentrated. The residue was purified by silica gel chromatography $\left(0 \rightarrow 5 \% \mathrm{CH}_{2} \mathrm{Cl}_{2}\right.$ in hexane) to give $2.4 \mathrm{~g}(39.7 \%)$ of a yellow solid. ${ }^{1} \mathrm{H}$ NMR $\left(400 \mathrm{MHz}, \mathrm{CDCl}_{3}\right) \delta 7.42(\mathrm{~m}, 4 \mathrm{H}), 7.18-7.12(\mathrm{~m}$, 4H), 2.37 (s, 6H). ${ }^{13} \mathrm{C}$ NMR (101 MHz, $\left.\mathrm{CDCl}_{3}\right) \delta 138.18,131.45,129.10,120.39,88.91,21.52$.

9-Bromoanthracene. In a $250 \mathrm{~mL}$ round bottom flask was added anthracene (3.00 g, $16.8 \mathrm{~mol})$ and $\mathrm{CuBr}_{2}(7.53$ $\mathrm{g}, 33.7 \mathrm{~mol})$ in $\mathrm{CHCl}_{3}(150 \mathrm{~mL})$. The reaction mixture was reflux overnight and cooled to room temperature. The solution was directly filtered through celite and the organic solvent was evaporated. The residue was purified by silica gel chromatography (100\% hexane) to give $3.6 \mathrm{~g}(83.7 \%)$ of a yellow solid. Further purification could 
be accomplished via recrystallization with ${ }^{i} \mathrm{PrOH} .{ }^{1} \mathrm{H}$ NMR $\left(400 \mathrm{MHz}, \mathrm{CDCl}_{3}\right) \delta 8.52(\mathrm{~d}, J=8.9 \mathrm{~Hz}, 2 \mathrm{H}), 8.45$ (s, 1H), $8.01(\mathrm{~d}, J=8.4 \mathrm{~Hz}, 2 \mathrm{H}), 7.61(\mathrm{dd}, J=8.3,7.1 \mathrm{~Hz}, 2 \mathrm{H}), 7.54-7.48(\mathrm{~m}, 2 \mathrm{H}) .{ }^{13} \mathrm{C}$ NMR $(101 \mathrm{MHz}$, $\left.\mathrm{CDCl}_{3}\right) \delta 132.12,130.55,128.59,127.60,127.18,127.10,125.61,122.35$.

1,2-Di-p-tolylaceanthrylene (2). In a glovebox were combined 1,2-di-p-tolylethyne (600 mg, $2.91 \mathrm{mmol}), 9$ bromoanthracene $(748 \mathrm{mg}, 2.91 \mathrm{mmol}), \mathrm{Pd}_{2}(\mathrm{dba})_{3}(266 \mathrm{mg}, 0.291 \mathrm{mmol}), \mathrm{P}(\mathrm{o}-\mathrm{tol})_{3}(132 \mathrm{mg}, 0.436 \mathrm{mmol})$, KOAc (735 mg, $8.90 \mathrm{mmol}), \mathrm{LiCl}(123 \mathrm{mg}, 2.91 \mathrm{mmol})$ and DMF $(30 \mathrm{~mL})$. The reaction vessel was sealed in a glass pressure tube and heated at $130{ }^{\circ} \mathrm{C}$ overnight. The reaction mixture was then cooled to room temperature and poured into water $(100 \mathrm{~mL})$. Diethyl ether $(200 \mathrm{~mL})$ was added and the mixture was extracted with water ( 2 X $100 \mathrm{~mL}$ ). The organic layer was dried over $\mathrm{Na}_{2} \mathrm{SO}_{4}$ and concentrated. The residue was purified by silica gel chromatography $\left(0 \rightarrow 10 \% \mathrm{CH}_{2} \mathrm{Cl}_{2}\right.$ in hexane) to give $786 \mathrm{mg}(70.8 \%)$ of a dark red solid. ${ }^{1} \mathrm{H}$ NMR (400 $\left.\mathrm{MHz}, \mathrm{CDCl}_{3}\right) \delta 8.49(\mathrm{~s}, 1 \mathrm{H}), 8.08(\mathrm{~d}, J=8.5 \mathrm{~Hz}, 1 \mathrm{H}), 8.03(\mathrm{~d}, J=8.4 \mathrm{~Hz}, 1 \mathrm{H}), 7.86(\mathrm{~d}, J=6.7 \mathrm{~Hz}, 1 \mathrm{H}), 7.81$ $(\mathrm{d}, J=8.7 \mathrm{~Hz}, 1 \mathrm{H}), 7.65-7.60(\mathrm{~m}, 1 \mathrm{H}), 7.39(\mathrm{~d}, J=6.6 \mathrm{~Hz}, 2 \mathrm{H}), 7.36(\mathrm{~d}, J=8.3 \mathrm{~Hz}, 1 \mathrm{H}), 7.31-7.28(\mathrm{~m}, 2 \mathrm{H})$, 7.26-7.23 (m, 2H), $7.13(\mathrm{~d}, J=7.6 \mathrm{~Hz}, 2 \mathrm{H}), 2.46(\mathrm{~s}, 3 \mathrm{H}), 2.36(\mathrm{~s}, 3 \mathrm{H}) .{ }^{13} \mathrm{C} \mathrm{NMR}\left(101 \mathrm{MHz}, \mathrm{CDCl}_{3}\right) \delta 140.24$, 139.94, 137.24, 136.87, 136.20, 134.96, 134.79, 134.56, 132.38, 130.61, 130.51, 130.14, 129.12, 128.89, 128.67, $128.06,127.23,127.18,126.39,126.20,125.69,125.64,124.42,124.40,21.54,21.34$. LRMS (EI +) 382.3; HRMS (EI+) m/z for $\mathrm{C}_{30} \mathrm{H}_{22}$ calcd 382.1722, found 382.1723.

6-Bromo-1,2-di-p-tolylaceanthrylene (3). In a $100 \mathrm{~mL}$ round bottom flask was stirred 2 (720 mg, $1.88 \mathrm{mmol})$ in chloroform $(20 \mathrm{~mL})$ while $\mathrm{Br}_{2}(301 \mathrm{mg}, 1.88 \mathrm{mmol})$ was added dropwise. The mixture was stirred for $2 \mathrm{~h}$. $\mathrm{CH}_{2} \mathrm{Cl}_{2}(50 \mathrm{~mL})$ was added and the mixture was extracted with water $(2 \mathrm{X} 100 \mathrm{~mL})$. The organic layer was dried over $\mathrm{Na}_{2} \mathrm{SO}_{4}$ and concentrated. The residue was purified by silica gel chromatography $\left(0 \rightarrow 10 \% \mathrm{CH}_{2} \mathrm{Cl}_{2}\right.$ in hexane) to give $426 \mathrm{mg}(49.1 \%)$ of a dark red solid. ${ }^{1} \mathrm{H} \mathrm{NMR}\left(400 \mathrm{MHz}, \mathrm{CDCl}_{3}\right) \delta 8.57(\mathrm{~d}, J=9.0 \mathrm{~Hz}, 1 \mathrm{H})$, $8.30(\mathrm{~d}, J=8.6 \mathrm{~Hz}, 1 \mathrm{H}), 7.83-7.78(\mathrm{~m}, 2 \mathrm{H}), 7.65(\mathrm{dd}, J=8.6,6.7 \mathrm{~Hz}, 1 \mathrm{H}), 7.51-7.45(\mathrm{~m}, 1 \mathrm{H}), 7.37(\mathrm{~d}, J=$ $7.9 \mathrm{~Hz}, 4 \mathrm{H}), 7.32-7.23(\mathrm{~m}, 5 \mathrm{H}), 7.13(\mathrm{~d}, J=7.9 \mathrm{~Hz}, 2 \mathrm{H}), 2.47$ (s, 3H), 2.37 (s, 3H). ${ }^{13} \mathrm{C} \mathrm{NMR}\left(101 \mathrm{MHz}, \mathrm{CDCl}_{3}\right)$ $\delta 140.36,139.97,137.55,137.06,136.43,134.75,134.31,132.59,131.93,130.87,130.42,129.97,129.16$, $129.10,128.89,128.46,127.92,127.23,127.06,126.24,126.11,125.78,124.83,124.80,21.49,21.32$. LRMS (EI+) 461.2; HRMS m/z for $\mathrm{C}_{30} \mathrm{H}_{21} \mathrm{Br}$ calcd 460.0827, found 460.0821. 
${ }^{13}$ C-labeled 9,9-didodecyl-2,7-diethynylfluorene (i). In a glovebox, 2,7-dibromo-9,9-didodecyl-fluorene (306 $\mathrm{mg}, 0.463 \mathrm{mmol}), \mathrm{Pd}\left(\mathrm{PPh}_{3}\right)_{2} \mathrm{Cl}_{2}(33 \mathrm{mg}, 0.047 \mathrm{mmol})$ and triphenylphosphine (24 mg, $\left.0.092 \mathrm{mmol}\right)$ were loaded into a $100 \mathrm{~mL}$ pressure tube and dissolved in THF $(25 \mathrm{~mL})$ and triethylamine $(5 \mathrm{~mL})$. The solution was stirred for $3 \mathrm{~min}$ followed by the addition of $\mathrm{CuI}(9 \mathrm{mg}, 0.05 \mathrm{mmol})$. The solution was further stirred for $3 \mathrm{~min}$ and ${ }^{13} \mathrm{C}-$ labeled TMS-acetylene (100 mg, $1.02 \mathrm{mmol})$ was added via syringe and the reaction flask was sealed, removed from the glovebox, and heated overnight at $65^{\circ} \mathrm{C}$. Upon cooling, the solution was filtered and concentrated. The residue was purified via silica gel chromatography (100\% hexane) to give $245 \mathrm{mg}(77.5 \%)$ of a yellow oil. In a $250 \mathrm{~mL}$ round bottom flask, the resulting oil $(245 \mathrm{mg}, 0.35 \mathrm{mmol})$ was dissolved in THF (20 mL), methanol (10 $\mathrm{mL}$ ), and $20 \% \mathrm{KOH}(\mathrm{aq}, 8 \mathrm{~mL}$ ) and stirred overnight at room temperature. The mixture was poured into a separatory funnel and diluted with diethyl ether $(100 \mathrm{~mL})$ and water $(500 \mathrm{~mL})$ and then separated. The organic layer was rinsed once more with water $(500 \mathrm{~mL})$ and then concentrated. The residue was purified by silica gel chromatography (100\% hexane) to give $122 \mathrm{mg}(62.9 \%)$ of a yellow oil. ${ }^{1} \mathrm{H}$ NMR $\left(400 \mathrm{MHz}, \mathrm{CDCl}_{3}\right) \delta 7.63(\mathrm{~d}$, $J=7.8 \mathrm{~Hz}, 2 \mathrm{H}), 7.50-7.47(\mathrm{~m}, 2 \mathrm{H}), 7.45(\mathrm{~d}, J=5.4 \mathrm{~Hz}, 2 \mathrm{H}), 3.52(\mathrm{~s}, 0.25 \mathrm{H}), 3.39(\mathrm{~s}, 0.25 \mathrm{H}), 2.90(\mathrm{~s}, 0.25 \mathrm{H})$, $2.77(\mathrm{~s}, 0.25 \mathrm{H}), 1.97-1.89(\mathrm{~m}, 4 \mathrm{H}), 1.32-0.96(\mathrm{~m}, 40 \mathrm{H}), 0.86(\mathrm{t}, J=6.9 \mathrm{~Hz}, 6 \mathrm{H}) .{ }^{13} \mathrm{C} \mathrm{NMR}\left(101 \mathrm{MHz}, \mathrm{CDCl}_{3}\right)$ $\delta 151.06,140.98,132.06,130.46,127.32,125.76,121.25,120.77,120.38,119.21,85.71,85.67,85.21,85.16$, $83.97,83.92,83.46,83.41,79.32,77.57,76.88,75.14,55.17,41.29,40.24,39.21,33.11,31.94,30.85,30.59$, $29.90,29.59,29.35,28.69,28.29,27.98,24.15,23.99,23.68,22.84,22.69,22.36,14.70,13.58,12.45$.

2,7-Dibromo-9-(2-octyldecyl)-9H-carbazole (ii). In a $100 \mathrm{~mL}$ round bottom flask was stirred 2,2-dibromo-9Hcarbazole $(2.00 \mathrm{~g}, 6.15 \mathrm{mmol})$ in $\mathrm{DMF}(30 \mathrm{~mL})$ at $0{ }^{\circ} \mathrm{C} . \mathrm{NaH}(205 \mathrm{mg}, 8.54 \mathrm{mmol})$ was added in portions over $10 \mathrm{~min}$. The reaction mixture was then stirred for another $30 \mathrm{~min}$ at room temperature. 1-Bromo-2-octyldodecane ( $2.89 \mathrm{~g}, 8.00 \mathrm{mmol}$ ) was added subsequently and the reaction mixture was stirred overnight at room temperature. Diethyl ether $(200 \mathrm{~mL})$ was added and the mixture was extracted with water $(2 \mathrm{X} 100 \mathrm{~mL})$. The organic layer was dried with $\mathrm{Na}_{2} \mathrm{SO}_{4}$ and concentrated. The residue was purified by silica gel chromatography (100\% hexane) to give $3.21 \mathrm{~g}(86.3 \%)$ of a colorless oil. ${ }^{1} \mathrm{H}$ NMR $\left(400 \mathrm{MHz}, \mathrm{CDCl}_{3}\right) \delta 7.88(\mathrm{~d}, J=8.3 \mathrm{~Hz}, 2 \mathrm{H}), 7.50(\mathrm{~d}, J=1.5$ $\mathrm{Hz}, 2 \mathrm{H}), 7.33(\mathrm{dd}, J=8.3,1.6 \mathrm{~Hz}, 2 \mathrm{H}), 4.05(\mathrm{t}, J=6.7 \mathrm{~Hz}, 2 \mathrm{H}), 2.12-2.02(\mathrm{~m}, 1 \mathrm{H}), 1.41-1.15(\mathrm{~m}, 32 \mathrm{H}), 0.92$ $-0.83(\mathrm{~m}, 6 \mathrm{H}) .{ }^{13} \mathrm{C} \mathrm{NMR}\left(101 \mathrm{MHz}, \mathrm{CDCl}_{3}\right) \delta 141.77,122.46,121.34,121.18,119.61,112.26,47.81,37.54$ 
$31.92,31.86,31.65,29.90,29.61,29.55,29.49,29.33,29.26,26.38,22.70,22.66,14.12$.

9-(2-Octyl-dodecyl)-2,7-bis-trimethylsilanylethynyl-9H-carbazole (iii). In a glovebox were combined ii (1.00 $\mathrm{g}, 1.65 \mathrm{mmol}), \mathrm{Pd}\left(\mathrm{PPh}_{3}\right)_{2} \mathrm{Cl}_{2}(58 \mathrm{mg}, 0.083 \mathrm{mmol}), \mathrm{PPh}_{3}(43 \mathrm{mg}, 0.16 \mathrm{mmol}), \mathrm{THF}(25 \mathrm{~mL})$ and $\mathrm{NEt}_{3}(5 \mathrm{~mL})$. After stirring $3 \mathrm{~min}, \mathrm{CuI}(16 \mathrm{mg}, 0.083 \mathrm{mmol})$ was added and the solution was stirred another $1 \mathrm{~min}$. TMSacetylene $(0.70 \mathrm{~mL}, 5.0 \mathrm{mmol})$ was then added and the reaction vessel was sealed and heated at $60{ }^{\circ} \mathrm{C}$ overnight. The reaction mixture was cooled and then concentrated. The residue was purified by silica gel chromatography (100\% hexane) to give $0.89 \mathrm{~g}(85.7 \%)$ of an off-white solid. ${ }^{1} \mathrm{H}$ NMR $\left(400 \mathrm{MHz}, \mathrm{CDCl}_{3}\right) \delta 7.95(\mathrm{~d}, J=8.1 \mathrm{~Hz}$, 2H), $7.47(\mathrm{~s}, 2 \mathrm{H}), 7.33(\mathrm{dd}, J=8.1,1.2 \mathrm{~Hz}, 2 \mathrm{H}), 4.10(\mathrm{~d}, J=7.6 \mathrm{~Hz}, 2 \mathrm{H}), 2.18-2.06(\mathrm{~m}, 1 \mathrm{H}), 1.41-1.14(\mathrm{~m}$, $32 \mathrm{H}), 0.92-0.83(\mathrm{~m}, 6 \mathrm{H}), 0.33-0.26(\mathrm{~m}, 18 \mathrm{H}) .{ }^{13} \mathrm{C} \mathrm{NMR}\left(101 \mathrm{MHz}, \mathrm{CDCl}_{3}\right) \delta 141.01,123.22,122.59,120.25$, $112.71,106.44,93.73,47.81,37.63,31.90,31.84,31.72,29.90,29.59,29.55,29.49,29.31,29.23,26.45,22.68$, $22.64,14.11,0.06$.

2,7-Diethynyl-9-(2-octyl-dodecyl)-9H-carbazole (iv). In a $100 \mathrm{~mL}$ round bottom flask were added iii (800 mg, $1.25 \mathrm{mmol}), \mathrm{THF}(25 \mathrm{~mL}), \mathrm{MeOH}(13 \mathrm{~mL})$, and a $20 \% \mathrm{KOH}$ solution (aq, $10 \mathrm{~mL})$. This solution was stirred overnight at room temperature and then diluted with ethyl ether $(150 \mathrm{~mL})$ and brine $(50 \mathrm{~mL})$. The organic layer was collected and concentrated. The residue was purified by silica gel chromatography (100\% hexane) to give $0.48 \mathrm{~g}(77.4 \%)$ of a yellow oil. ${ }^{1} \mathrm{H}$ NMR $\left(400 \mathrm{MHz}, \mathrm{CDCl}_{3}\right) \delta 8.01-7.97(\mathrm{~m}, 2 \mathrm{H}), 7.52(\mathrm{~s}, 2 \mathrm{H}), 7.36(\mathrm{dd}, J=$ $8.0,1.2 \mathrm{~Hz}, 2 \mathrm{H}), 4.11(\mathrm{~d}, J=7.6 \mathrm{~Hz}, 2 \mathrm{H}), 3.15(\mathrm{~s}, 2 \mathrm{H}), 2.16-2.06(\mathrm{~m}, 1 \mathrm{H}), 1.38-1.14(\mathrm{~m}, 32 \mathrm{H}), 0.88(\mathrm{td}, J=$ 6.8, 4.1 Hz, 6H). ${ }^{13} \mathrm{C}$ NMR (101 MHz, $\left.\mathrm{CDCl}_{3}\right) \delta 140.98,123.19,122.76,120.41,119.31,113.03,84.90,76.84$, $76.81,47.81,37.70,31.91,31.85,31.73,29.91,29.60,29.59,29.54,29.49,29.32,29.24,26.44,22.69,22.65$, 14.13.

1,4-Dibromo-2,5-bis-octyloxybenzene (v). In a $250 \mathrm{~mL}$ round bottom flask was stirred 1,4bis(octyloxy)benzene $(4.89 \mathrm{~g}, 14.6 \mathrm{mmol})$ in $\mathrm{CH}_{2} \mathrm{Cl}_{2}(150 \mathrm{~mL})$ while $\mathrm{Br}_{2}(5.13 \mathrm{~g}, 32.1 \mathrm{mmol})$ was added dropwise at $0{ }^{\circ} \mathrm{C}$. The solution mixture was allowed to warm to room temperature and stirred overnight. $\mathrm{CH}_{2} \mathrm{Cl}_{2}$ $(100 \mathrm{~mL})$ was added and the mixture was extracted with water $(2 \mathrm{X} 50 \mathrm{~mL})$. The organic layer was dried over $\mathrm{Na}_{2} \mathrm{SO}_{4}$ and concentrated. The residue was purified by silica gel chromatography (100\% hexane) to give $5.28 \mathrm{~g}$ 
(73.4\%) of a colorless oil. ${ }^{1} \mathrm{H}$ NMR $\left(400 \mathrm{MHz}, \mathrm{CDCl}_{3}\right) \delta 7.08(\mathrm{~s}, 2 \mathrm{H}), 3.94(\mathrm{t}, J=6.5 \mathrm{~Hz}, 4 \mathrm{H}), 1.85-1.74$ (m, $4 \mathrm{H}), 1.47-1.23(\mathrm{~m}, 20 \mathrm{H}), 0.88(\mathrm{t}, J=6.8 \mathrm{~Hz}, 6 \mathrm{H}) .{ }^{13} \mathrm{C} \mathrm{NMR}\left(101 \mathrm{MHz}, \mathrm{CDCl}_{3}\right) \delta 150.06,118.45,111.12$, $70.30,31.91,29.65,29.63,29.57,29.53,29.34,29.28,29.11,25.92,22.68,14.11$.

1,4-Bis-octyloxy-2,5-bis-trimethylsilanylethynylbenzene (vi). In a glovebox were combined $\mathbf{v}$ ( $3.70 \mathrm{~g}, 7.52$ mmol), $\mathrm{Pd}\left(\mathrm{PPh}_{3}\right)_{2} \mathrm{Cl}_{2}(267 \mathrm{mg}, 0.380 \mathrm{mmol}), \mathrm{PPh}_{3}(197 \mathrm{mg}, 0.751 \mathrm{mmol}), \mathrm{THF}(75 \mathrm{~mL})$ and $\mathrm{NEt}_{3}(15 \mathrm{~mL})$. After stirring $3 \mathrm{~min}$, CuI (72 mg, $0.38 \mathrm{mmol})$ was added and the solution was stirred another $1 \mathrm{~min}$. TMSacetylene $(3.10 \mathrm{~mL}, 22.6 \mathrm{mmol})$ was then added and the reaction vessel was sealed and heated at $60^{\circ} \mathrm{C}$ overnight. The reaction mixture was cooled and then concentrated. The residue was purified by silica gel chromatography (100\% hexane) to give $3.6 \mathrm{~g}(88 \%)$ of an off-white solid. ${ }^{1} \mathrm{H} \mathrm{NMR}\left(400 \mathrm{MHz}, \mathrm{CDCl}_{3}\right) \delta 6.88(\mathrm{~s}, 2 \mathrm{H}), 3.93(\mathrm{t}, J$ $=6.3 \mathrm{~Hz}, 4 \mathrm{H}), 1.82-1.73(\mathrm{~m}, 4 \mathrm{H}), 1.53-1.44(\mathrm{~m}, 4 \mathrm{H}), 1.37-1.23(\mathrm{~m}, 20 \mathrm{H}), 0.92-0.84(\mathrm{~m}, 6 \mathrm{H}), 0.25(\mathrm{~s}, 18 \mathrm{H})$. ${ }^{13} \mathrm{C} \mathrm{NMR}\left(101 \mathrm{MHz}, \mathrm{CDCl}_{3}\right) \delta 153.98,117.15,113.92,101.04,100.02,77.31,77.00,76.68,69.41,31.83,29.37$, $29.33,29.28,26.01,22.65,14.07,-0.07$.

1,4-Diethynyl-2,5-bis-octyloxy-benzene (vii). In a $100 \mathrm{~mL}$ round bottom flask were added vi (535 mg, 1.04 $\mathrm{mmol}), \mathrm{THF}(25 \mathrm{~mL}), \mathrm{MeOH}(13 \mathrm{~mL})$, and a $20 \% \mathrm{KOH}$ solution (aq, $10 \mathrm{~mL})$. This solution was stirred overnight at room temperature and then diluted with ethyl ether $(150 \mathrm{~mL})$ and brine $(50 \mathrm{~mL})$. The organic layer was collected and concentrated. The residue was purified by silica gel chromatography $\left(0 \rightarrow 10 \% \mathrm{CH}_{2} \mathrm{Cl}_{2}\right.$ in hexane) to give $0.33 \mathrm{~g}(85.3 \%)$ of a yellow solid. ${ }^{1} \mathrm{H}$ NMR $\left(400 \mathrm{MHz}, \mathrm{CDCl}_{3}\right) \delta 6.95(\mathrm{~s}, 2 \mathrm{H}), 3.97(\mathrm{t}, J=6.6 \mathrm{~Hz}, 4 \mathrm{H})$, $3.32(\mathrm{~s}, 2 \mathrm{H}), 1.83-1.76(\mathrm{~m}, 4 \mathrm{H}), 1.53-1.20(\mathrm{~m}, 20 \mathrm{H}), 0.88(\mathrm{t}, J=6.9 \mathrm{~Hz}, 6 \mathrm{H}) .{ }^{13} \mathrm{C} \mathrm{NMR}\left(101 \mathrm{MHz}, \mathrm{CDCl}_{3}\right) \delta$ $153.94,117.69,113.21,82.39,82.35,79.75,69.63,31.78,29.27,29.20,29.10,25.88,22.64,14.09$.

${ }^{13}$ C-labelled Poly(9,9-didodecyl-fluorene-2,7-ethynylene) (4). In a glovebox were combined 2,7-dibromo-9,9didodecyl-9H-fluorene (141 mg, $0.213 \mathrm{mmol}), \mathbf{i}$ (122 mg, $0.221 \mathrm{mmol}), \mathrm{Pd}\left(\mathrm{PPh}_{3}\right)_{4}(12 \mathrm{mg}, 0.010 \mathrm{mmol}), \mathrm{CuI}$ (2 $\mathrm{mg}, 0.01 \mathrm{mmol})$, toluene $(10 \mathrm{~mL})$ and diisopropylamine $(2 \mathrm{~mL})$. The reaction vessel was sealed and heated at 85 ${ }^{\circ} \mathrm{C}$ for 3 days. The reaction mixture was filtered and concentrated. The residue was repetitively precipitated from THF by dropwise addition to methanol, hexane, and then methanol to give $178 \mathrm{mg}$ (79.1\%) of a yellow solid. ${ }^{1} \mathrm{H}$ NMR $(400 \mathrm{MHz}$, THF-d 8$) \delta$ 7.95-7.50 (m, 6H), 2.65-1.85 (m, 4H), $1.54-0.36(\mathrm{~m}, 46 \mathrm{H}) .{ }^{13} \mathrm{C}$ NMR $(101$ 
MHz, THF-d $\left.\mathrm{d}_{8}\right) \delta 152.15,141.97,132.38,131.03,130.07,128.43,127.77,126.06,124.05,123.55,123.01$, $121.98,120.34,91.73,56.32,42.63,41.51,34.25,33.03,32.46,31.80,31.24,30.74,30.49,30.06,29.52,29.26$, $23.75,22.51,16.49,15.26,14.04,12.82 . \mathrm{Mn}=32,580, \mathrm{PDI}=2.5$.

${ }^{13}$ C-labeled Poly(9,9-didodecyl-fluorene-co-1,2-di-p-tolylcyclopenta[hi]aceanthrylene) (7). In a glovebox were combined 3 (111 mg, $0.241 \mathrm{mmol}), 4$ (25 mg, $0.048 \mathrm{mmol}), \mathrm{Pd}_{2}(\mathrm{dba})_{3}(2.2 \mathrm{mg}, 0.0024 \mathrm{mmol}), \mathrm{P}(\mathrm{o}-\mathrm{tol})_{3}$ (1.5 mg, $0.0048 \mathrm{mmol}), \mathrm{KOAc}(14 \mathrm{mg}, 0.14 \mathrm{mmol}), \mathrm{LiCl}(2 \mathrm{mg}, 0.048 \mathrm{mmol})$ and toluene/DMF (5mL / $5 \mathrm{~mL})$. The reaction vessel was sealed and heated at $130{ }^{\circ} \mathrm{C}$ for 6 days. The reaction mixture was filtered and concentrated. The concentrated residue was repetitively precipitated from THF by dropwise addition to methanol, hexane, and then methanol to give $21 \mathrm{mg}(75 \%)$ of a green solid. ${ }^{1} \mathrm{H} \mathrm{NMR}\left(400 \mathrm{MHz}, \mathrm{CD}_{2} \mathrm{Cl}_{2}\right) \delta$ 8.37-6.53 (m, 20H), 2.49-2.28 (m, 4H), 1.45-0.40 (m, 52H). ${ }^{13} \mathrm{C}$ NMR (101 MHz, THF-d 8 ) $\delta ~ 141.48, ~ 140.74$, $140.28,139.62,91.64,32.98,30.82,30.47,23.65,14.62 . \mathrm{Mn}=21,800, \mathrm{PDI}=1.6$.

Poly(9-[2-octyl]dodecyl)-carbazole-2,7-ethynylene) (5). In a glovebox were combined ii (239 mg, 0.395 mmol), iv (202 mg, $0.407 \mathrm{mmol}), \mathrm{Pd}\left(\mathrm{PPh}_{3}\right)_{4}(23 \mathrm{mg}, 0.02 \mathrm{mmol}), \mathrm{CuI}(3.8 \mathrm{mg}, 0.018 \mathrm{mmol})$, toluene (20 mL) and diisopropylamine $(4 \mathrm{~mL})$. The reaction vessel was sealed and heated at $85^{\circ} \mathrm{C}$ for 3 days. The reaction mixture was filtered and concentrated. The concentrated residue was repetitively precipitated from THF by dropwise addition to methanol, hexane, and then methanol to give $227 \mathrm{mg}(58.3 \%)$ of a yellow solid. ${ }^{1} \mathrm{H} \mathrm{NMR}(400 \mathrm{MHz}$, $\left.\mathrm{CDCl}_{3}\right) \delta 8.13-8.00(\mathrm{~m}, 2 \mathrm{H})$, 7.67-7.57 (m, 2H), 7.53-7.43 (m, 2H), 4.38-3.98 (m, 2H), 2.37-2.03 (m, $\left.1 \mathrm{H}\right), 1.60$ $-0.75(\mathrm{~m}, 38 \mathrm{H}) . \mathrm{M}_{\mathrm{n}}=20,890, \mathrm{PDI}=3.2$.

Poly(9-[2-octyl]dodecyl)-carbazole-co-1,2-di-p-tolylcyclopenta[hi]aceanthrylene (8). In a glovebox were combined 3 (194 mg, $0.420 \mathrm{mmol}), 5$ (39 mg, $0.083 \mathrm{mmol}), \mathrm{Pd}_{2}(\mathrm{dba})_{3}(3.8 \mathrm{mg}, 0.0042 \mathrm{mmol}), \mathrm{P}(\mathrm{o}-\mathrm{tol})_{3}(2.6 \mathrm{mg}$, $0.0084 \mathrm{mmol}), \mathrm{KOAc}(25 \mathrm{mg}, 0.25 \mathrm{mmol}), \mathrm{LiCl}(3.6 \mathrm{mg}, 0.084 \mathrm{mmol})$ and toluene/DMF (5mL / $5 \mathrm{~mL})$. The reaction vessel was sealed and heated at $130{ }^{\circ} \mathrm{C}$ for 6 days. The reaction mixture was filtered and concentrated. The concentrated residue was repetitively precipitated from THF by dropwise addition to methanol, hexane, and then methanol to give $41 \mathrm{mg}(60.5 \%)$ as green solid. ${ }^{1} \mathrm{H}$ NMR $\left(400 \mathrm{MHz}, \mathrm{CD}_{2} \mathrm{Cl}_{2}\right) \delta 8.00-7.00(\mathrm{~m}, 20 \mathrm{H}), 4.35$ $3.30(\mathrm{~m}, 2 \mathrm{H}), 2.55-2.20(\mathrm{~m}, 5 \mathrm{H}), 1.35-0.40(\mathrm{~m}, 44 \mathrm{H}) . \mathrm{M}_{\mathrm{n}}=13,030, \mathrm{PDI}=2.0$. 
Poly(2,5-dioctyloxyphenylene-1,4-ethynylene) (6). In a glovebox were combined v (312 mg, $0.634 \mathrm{mmol}$ ), vii (250 mg, $0.654 \mathrm{mmol}), \mathrm{Pd}\left(\mathrm{PPh}_{3}\right)_{4}(38 \mathrm{mg}, 0.032 \mathrm{mmol}), \mathrm{CuI}(6.1 \mathrm{mg}, 0.032 \mathrm{mmol})$, toluene $(20 \mathrm{~mL})$ and diisopropylamine $(4 \mathrm{~mL})$. The reaction vessel was sealed and heated at $85{ }^{\circ} \mathrm{C}$ for 3 days. The reaction mixture was filtered and concentrated. The residue was repetitively precipitated from THF by dropwise addition to methanol, hexane, and then methanol to give $213 \mathrm{mg}(43.7 \%)$ of a yellow solid. ${ }^{1} \mathrm{H}$ NMR $\left(400 \mathrm{MHz}, \mathrm{CDCl}_{3}\right) \delta$ $7.01(\mathrm{~s}, 2 \mathrm{H}), 4.12-3.91(\mathrm{~m}, 4 \mathrm{H}), 1.89-1.78(\mathrm{~m}, 4 \mathrm{H}), 1.58-1.12(\mathrm{~m}, 36 \mathrm{H}), 0.90-0.83(\mathrm{~m}, 6 \mathrm{H}) . \mathrm{Mn}=12,580$, PDI $=2.6$.

Poly(2,5-dioctyloxyphenylene-co-1,2-di-p-tolylcyclopenta[hi]aceanthrylene) (9). In a glovebox were combined 3 (194 mg, $0.420 \mathrm{mmol}), 6$ (30 mg, $0.083 \mathrm{mmol}), \mathrm{Pd}_{2}(\mathrm{dba})_{3}(3.8 \mathrm{mg}, 0.0042 \mathrm{mmol}), \mathrm{P}(\mathrm{o}-\mathrm{tol})_{3}(2.6 \mathrm{mg}$, $0.0084 \mathrm{mmol}), \mathrm{KOAc}(25 \mathrm{mg}, 0.25 \mathrm{mmol}), \mathrm{LiCl}(3.6 \mathrm{mg}, 0.084 \mathrm{mmol})$ and toluene/DMF (5mL / $5 \mathrm{~mL})$. The reaction vessel was sealed and heated at $130{ }^{\circ} \mathrm{C}$ for 6 days. The reaction mixture was filtered and concentrated. The concentrated residue was repetitively precipitated from THF by dropwise addition to methanol, hexane, and then methanol to give $24.8 \mathrm{mg}(43.5 \%)$ of a green solid. ${ }^{1} \mathrm{H}$ NMR $\left(400 \mathrm{MHz}, \mathrm{CD}_{2} \mathrm{Cl}_{2}\right) \delta 7.70-6.50$ (s, $\left.16 \mathrm{H}\right)$, 4.05-3.15 (m, 4H), 2.35-2.00 (m, 4H), 1.71-0.39 (m, 32H). $\mathrm{M}_{\mathrm{n}}=11,410$, PDI = 2.0. 


\section{1,2-di-p-tolylethyne}
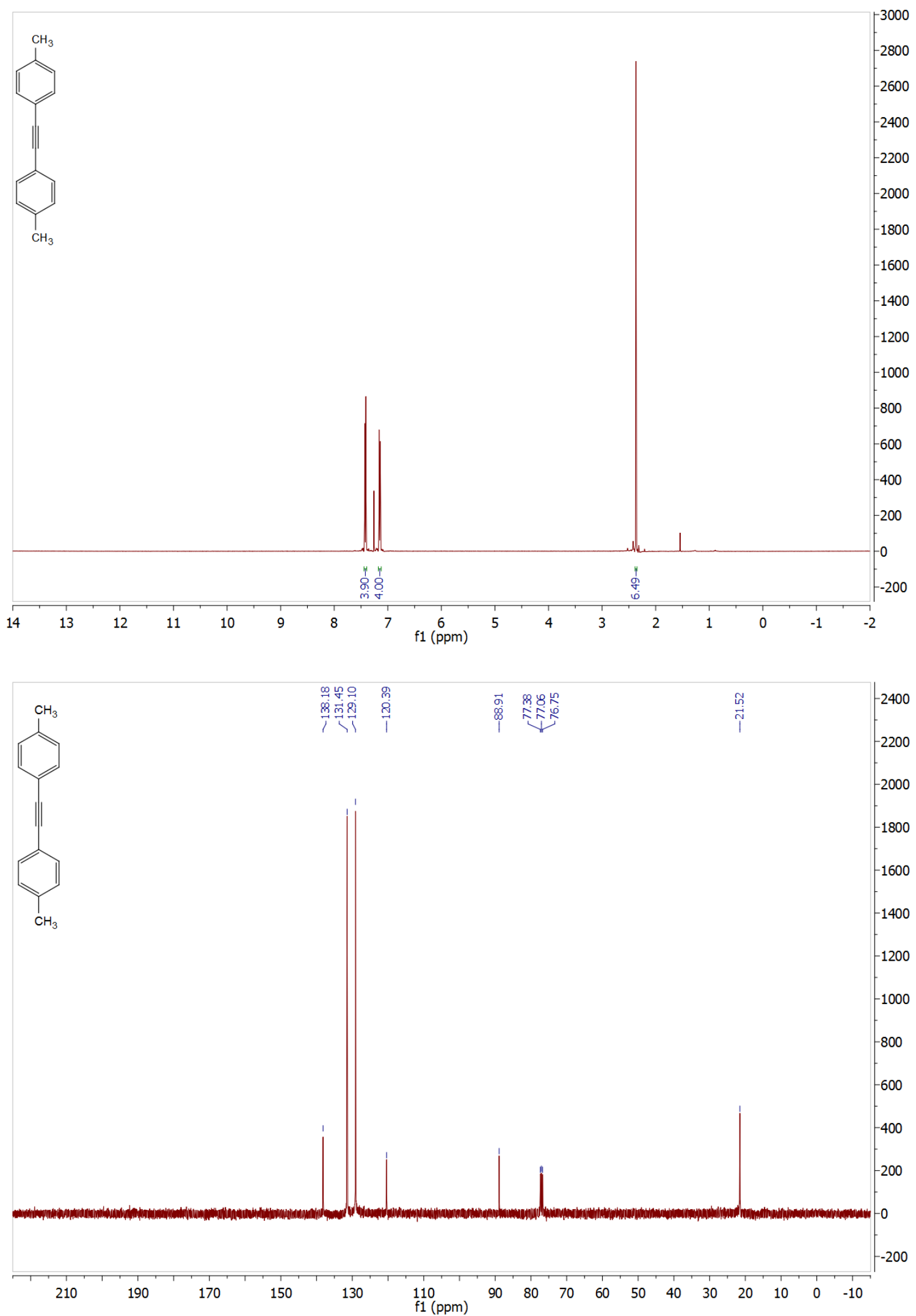


\section{9-Bromoanthracene}
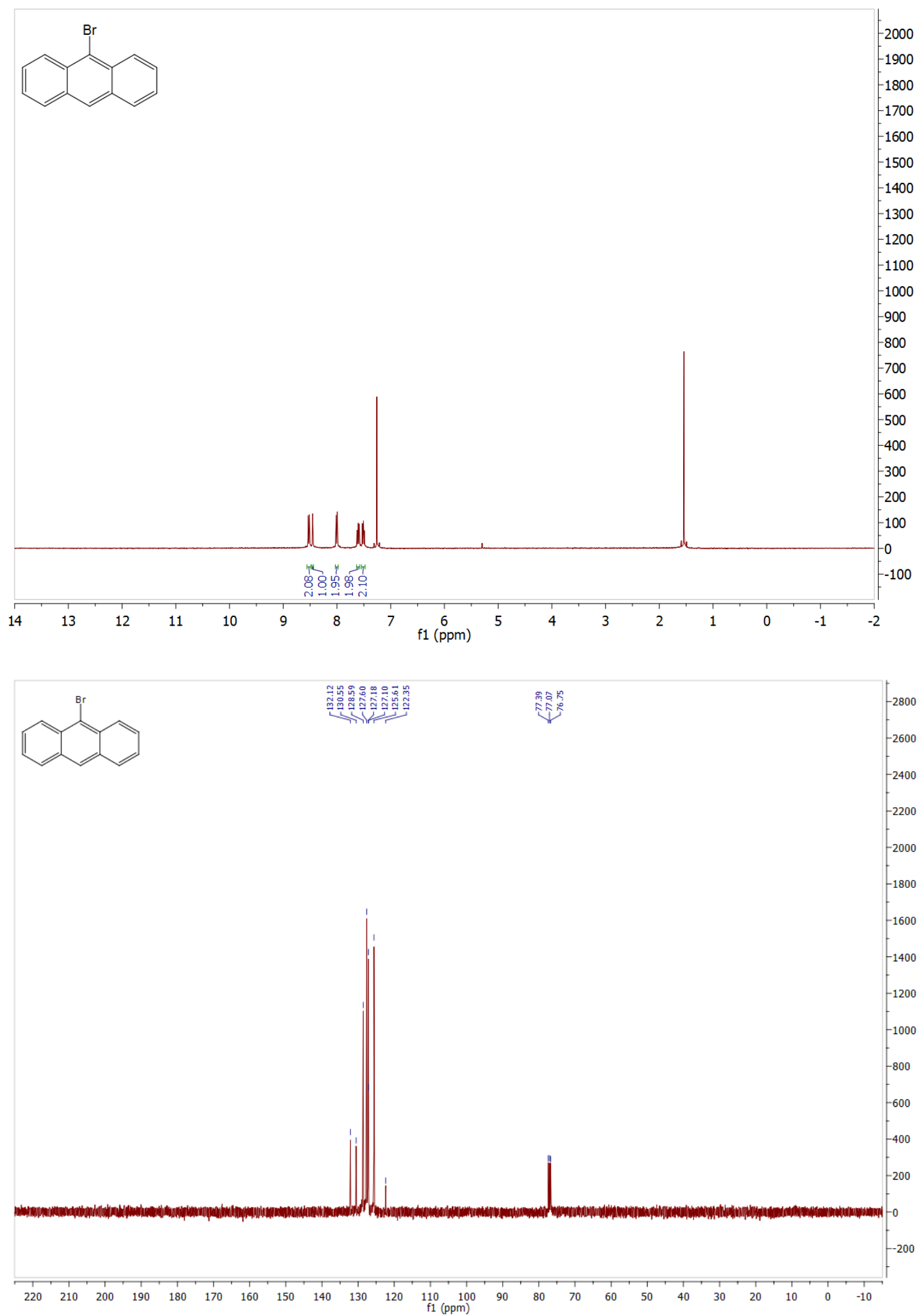


\section{Compound 2}
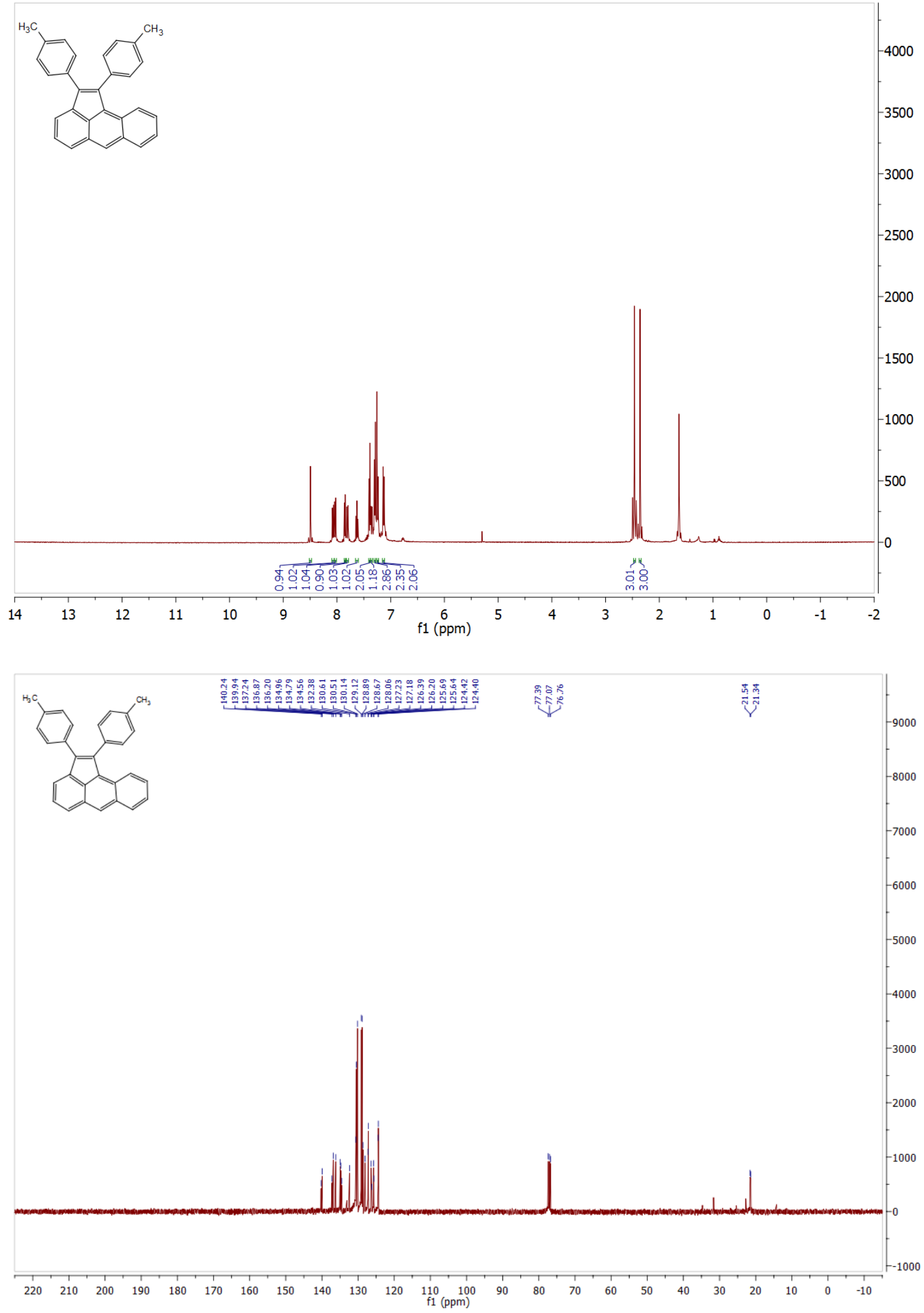


\section{Compound 3}
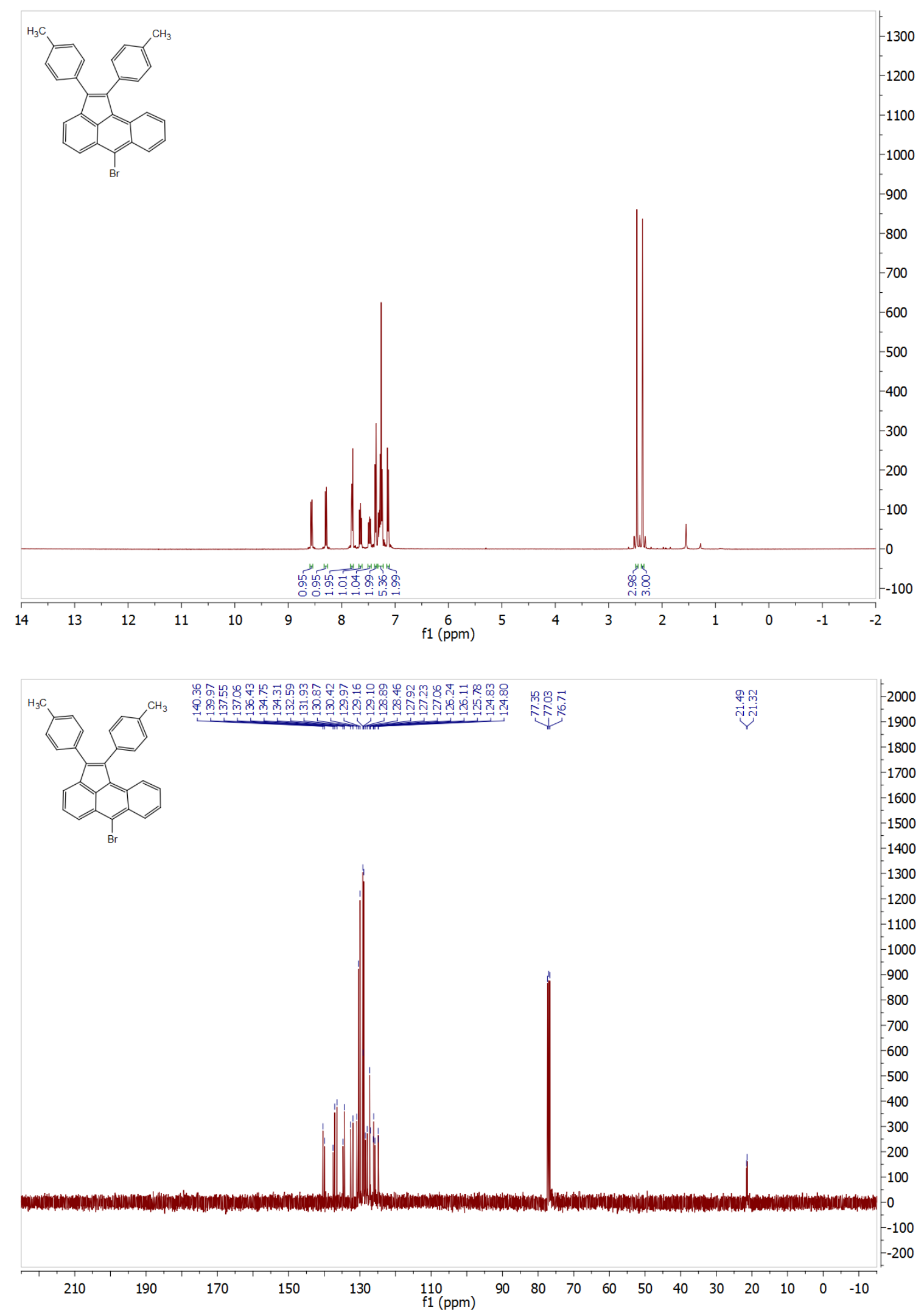


\section{Compound i}
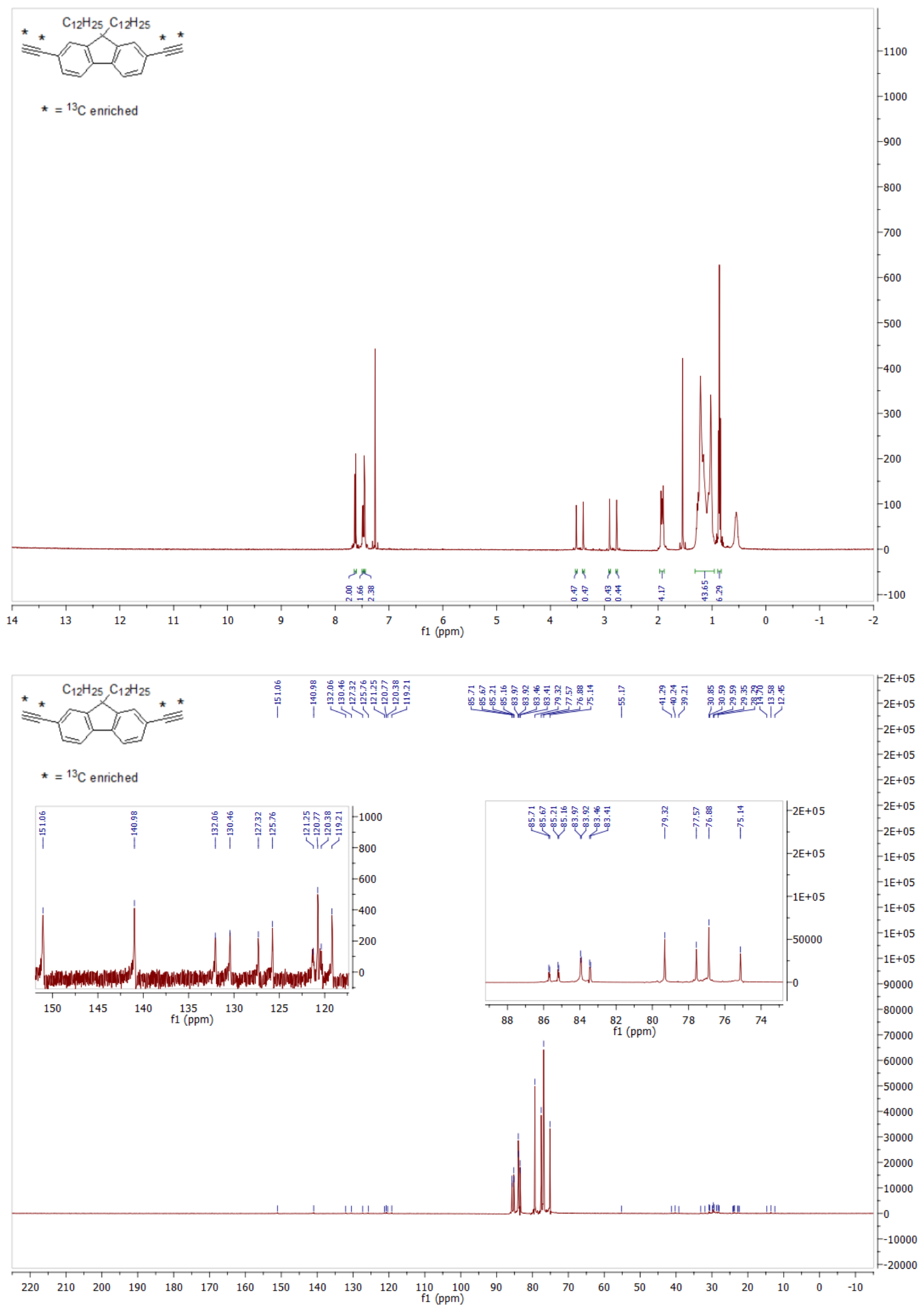


\section{Compound ii}
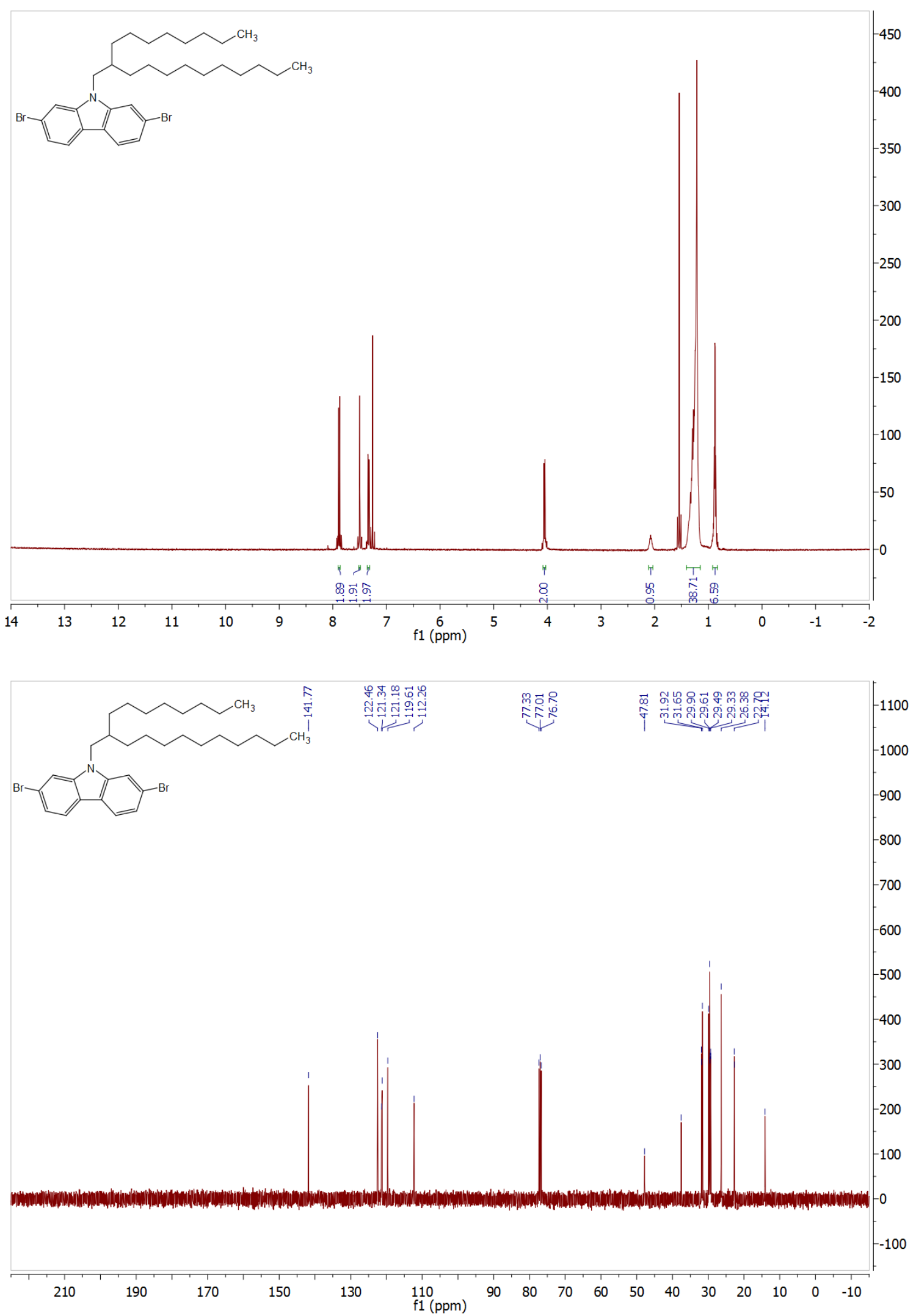


\section{Compound iii}
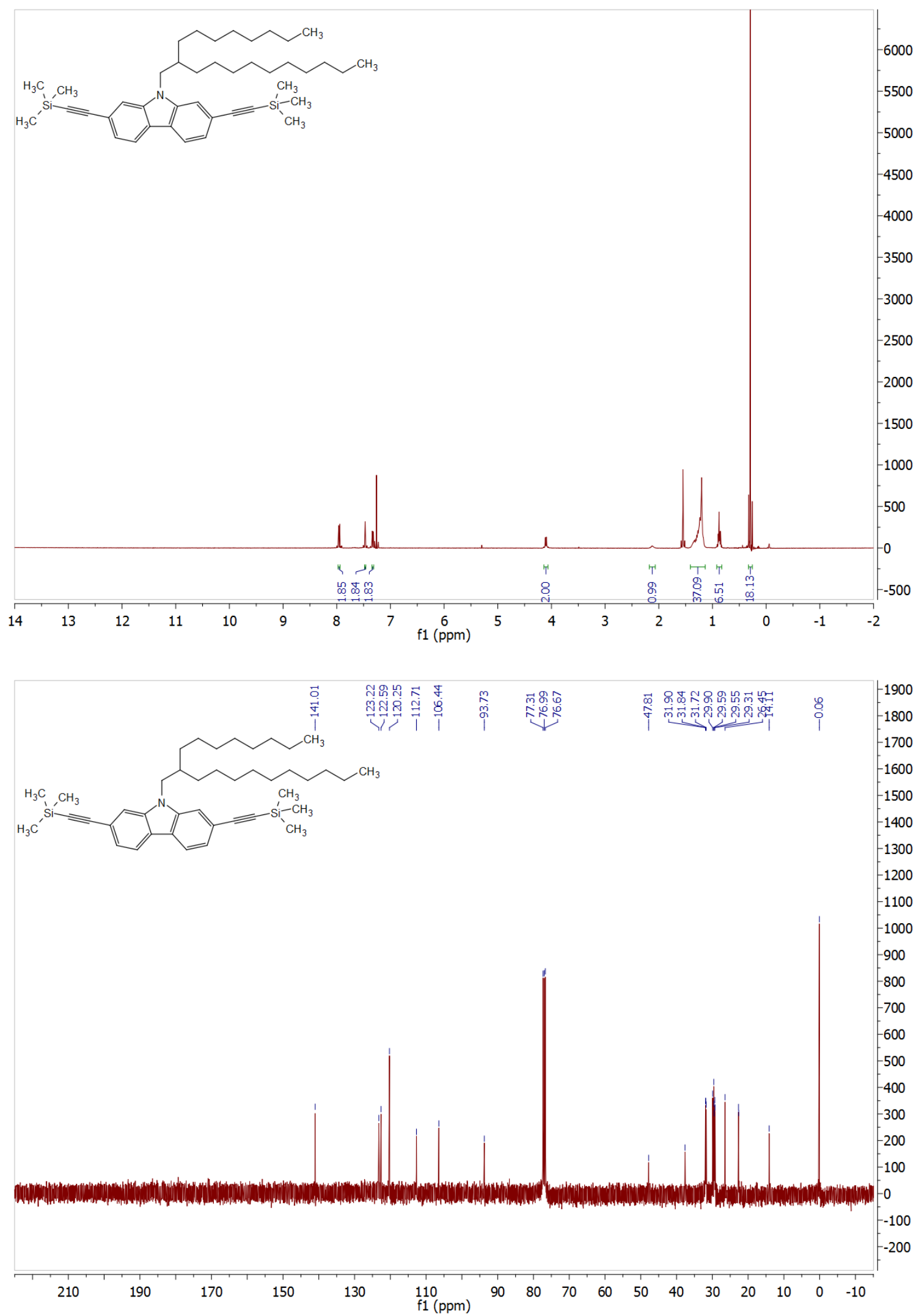


\section{Compound iv}
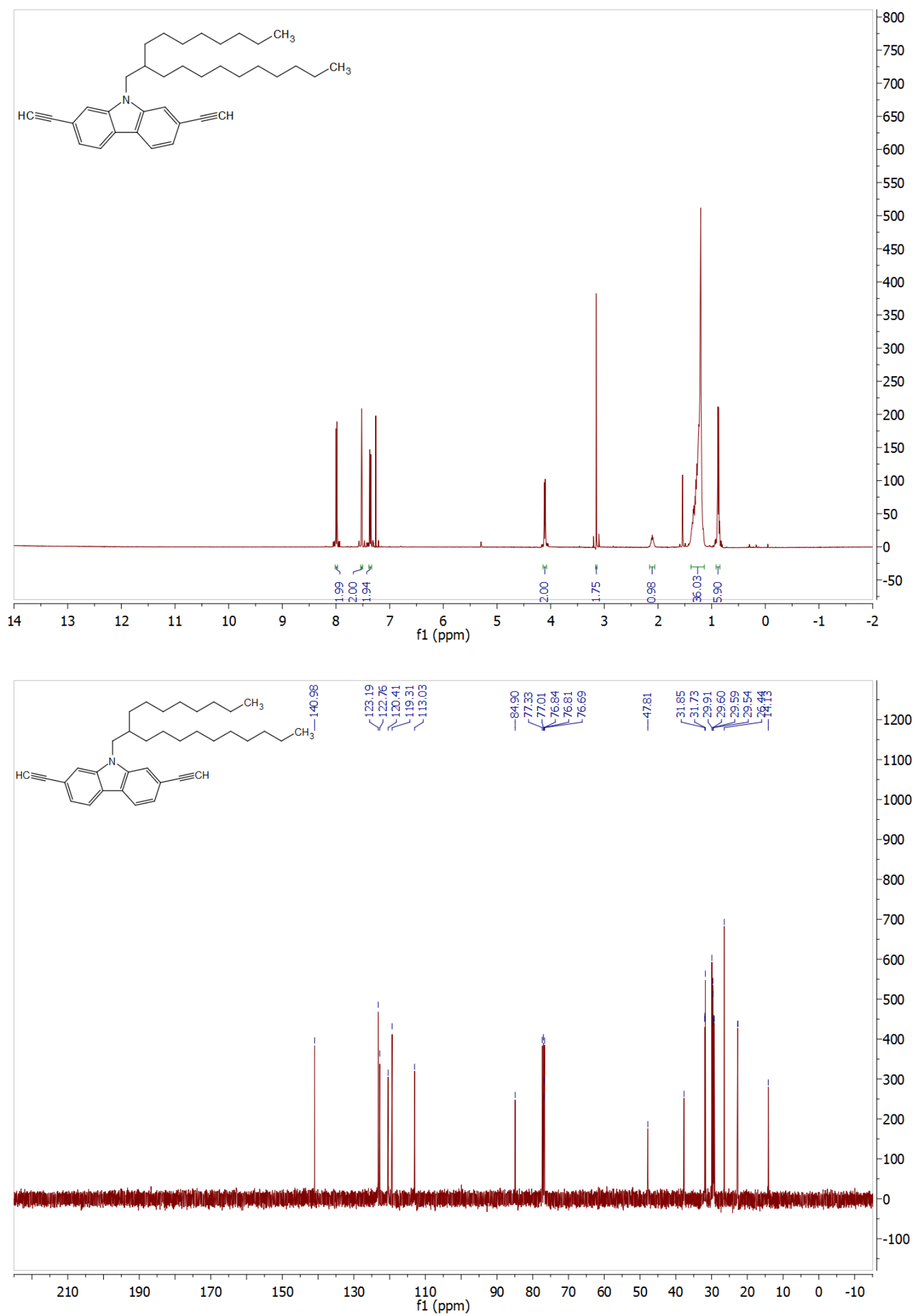


\section{Compound v}
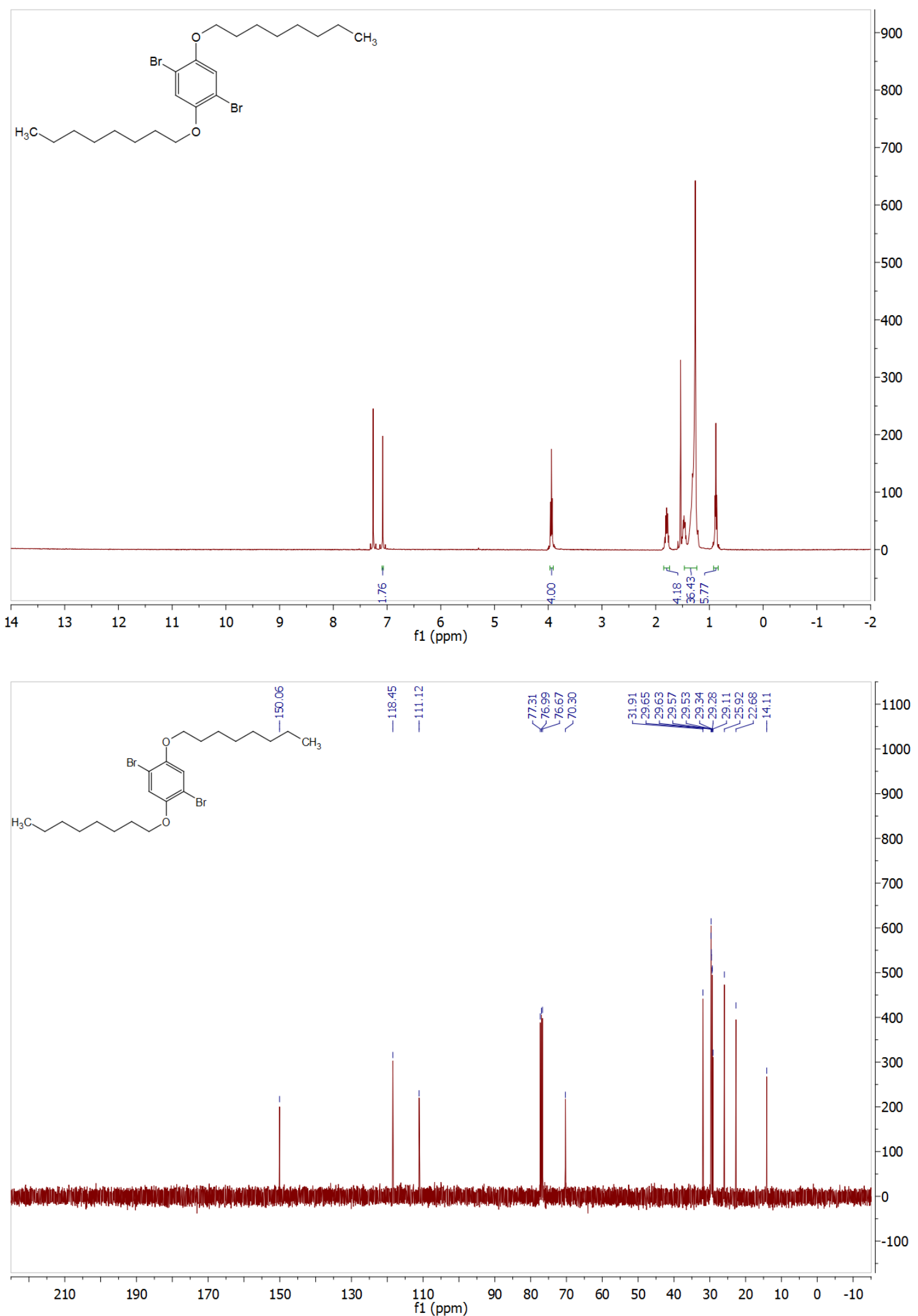


\section{Compound vi}
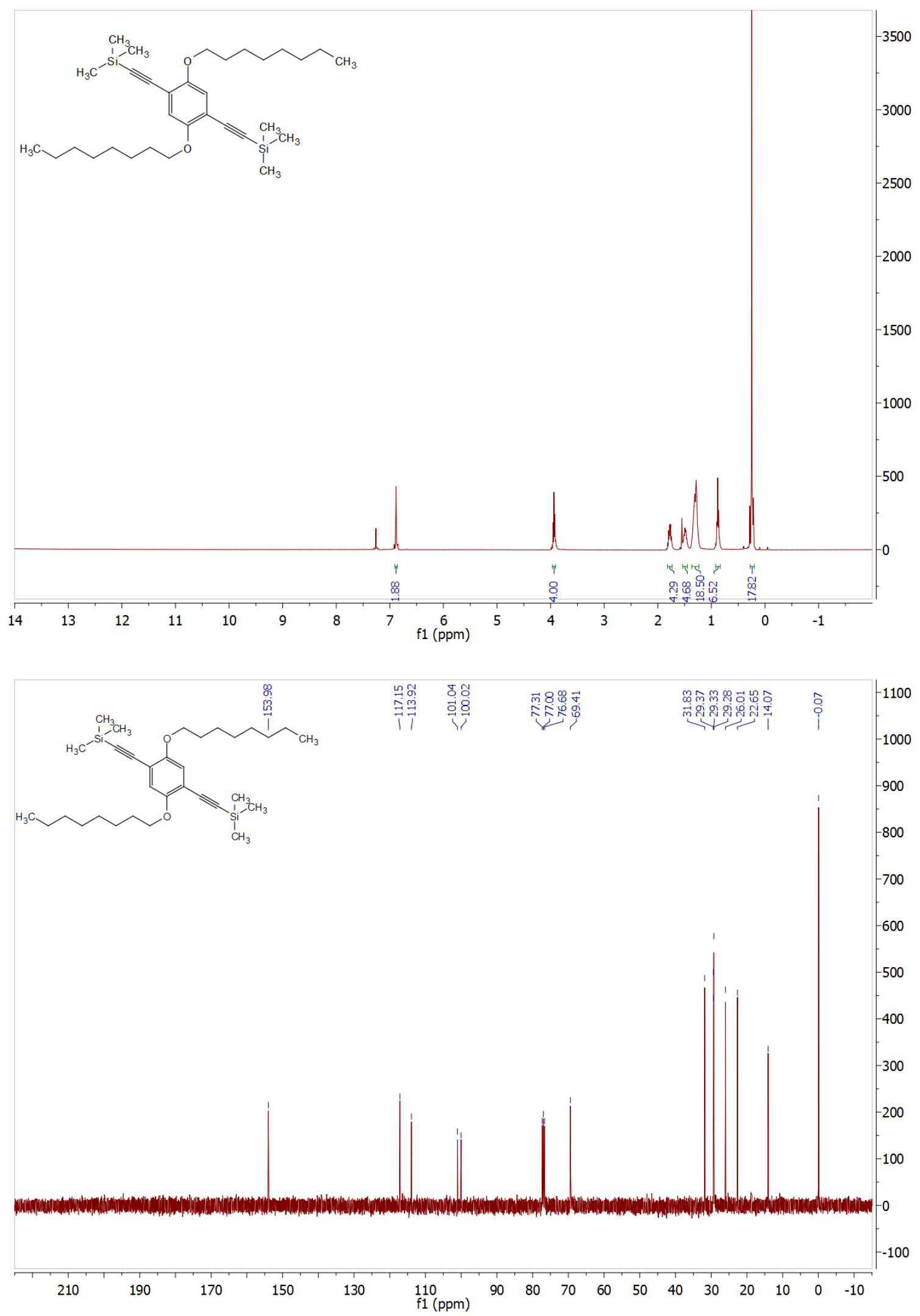


\section{Compound vii}
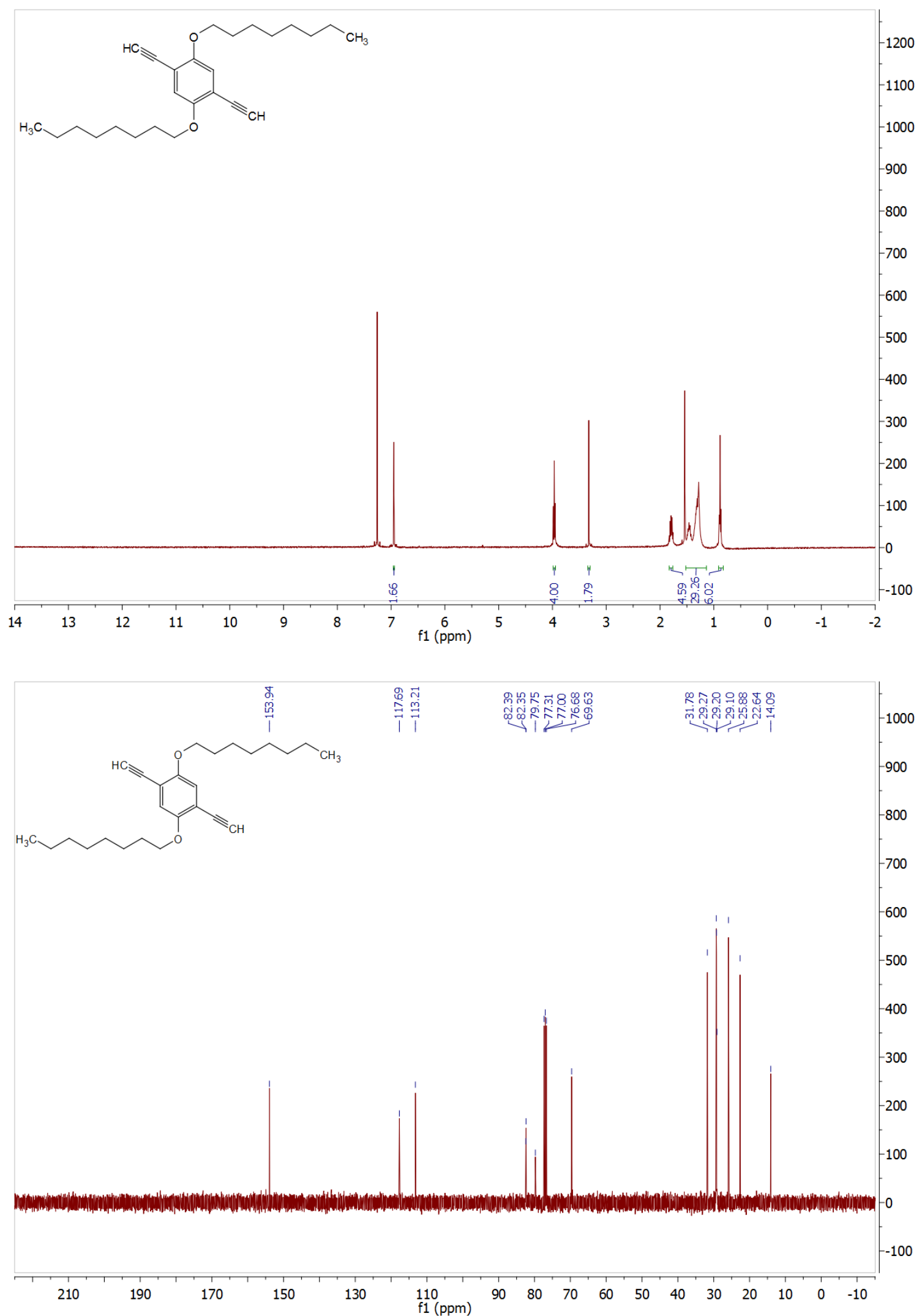


\section{Polymer 4}
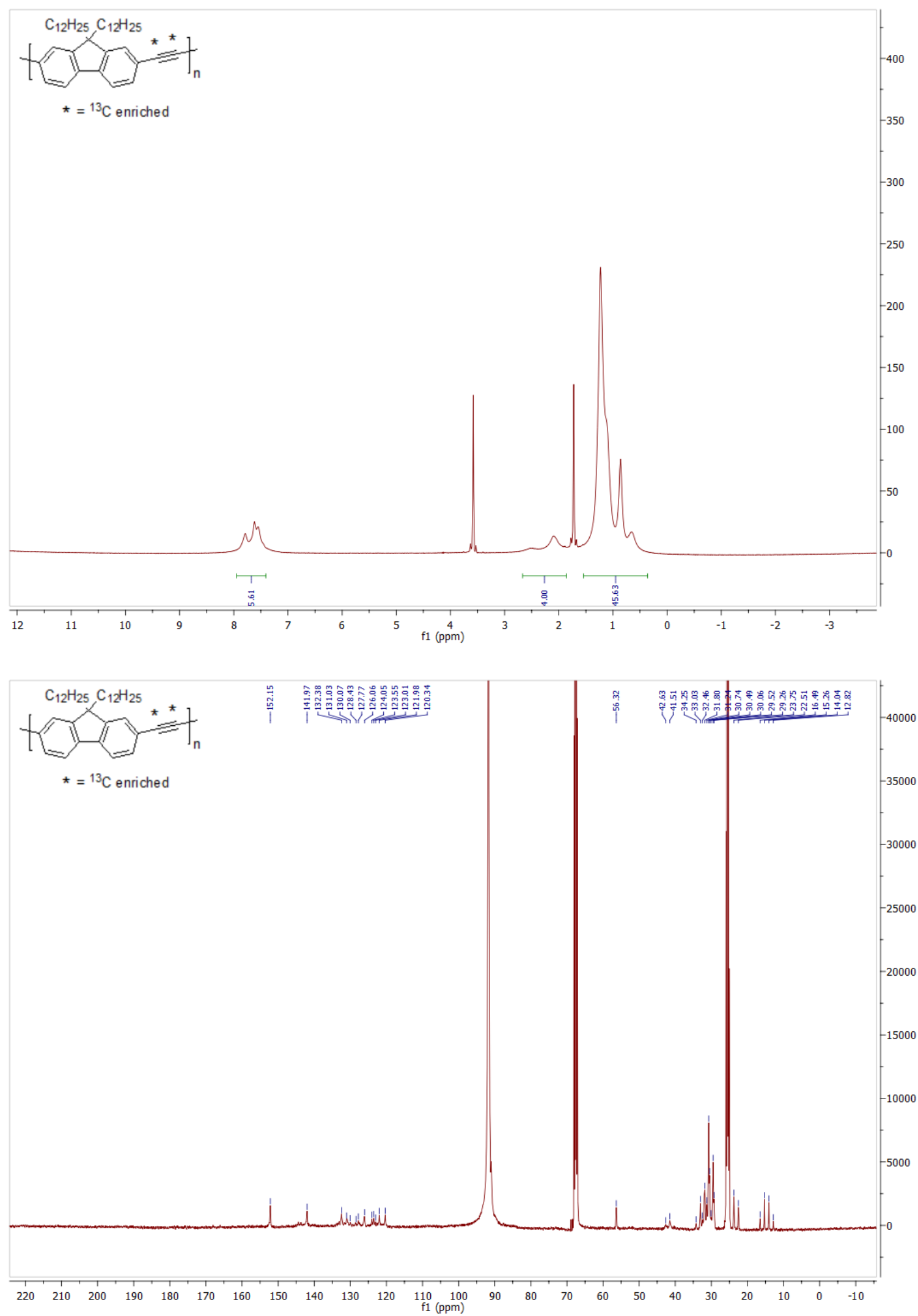


\section{Polymer 7}
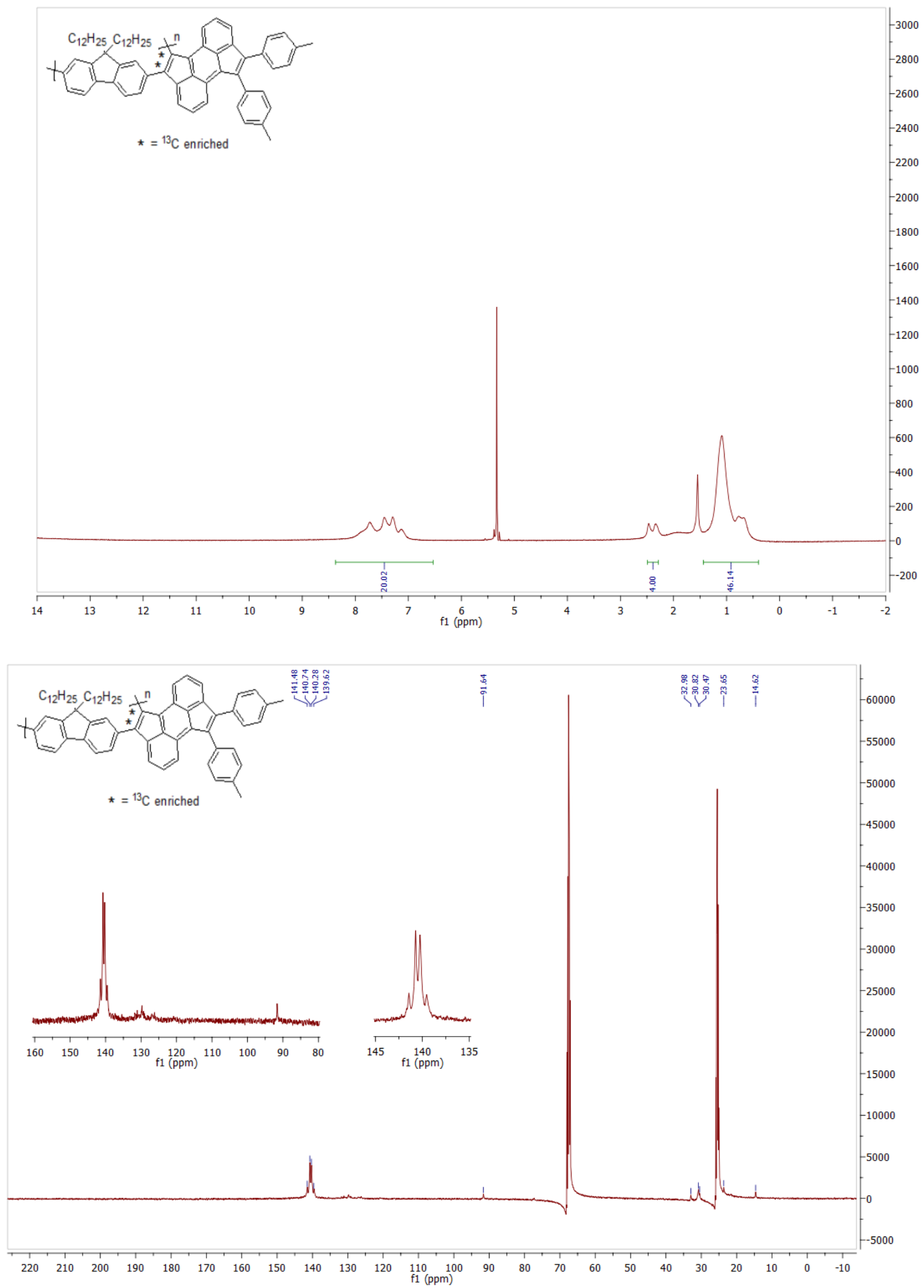


\section{Polymer 5}

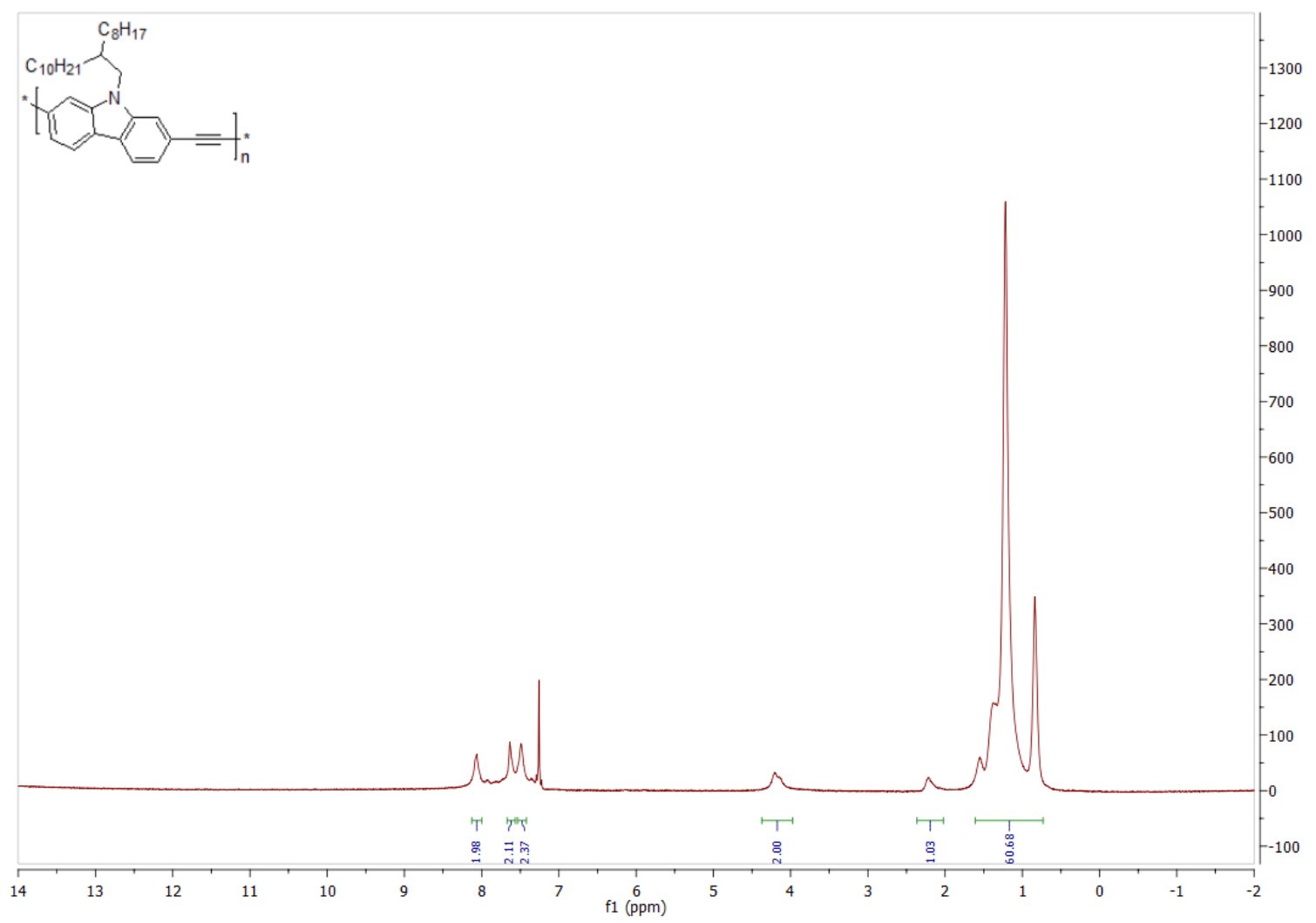




\section{Polymer 8}

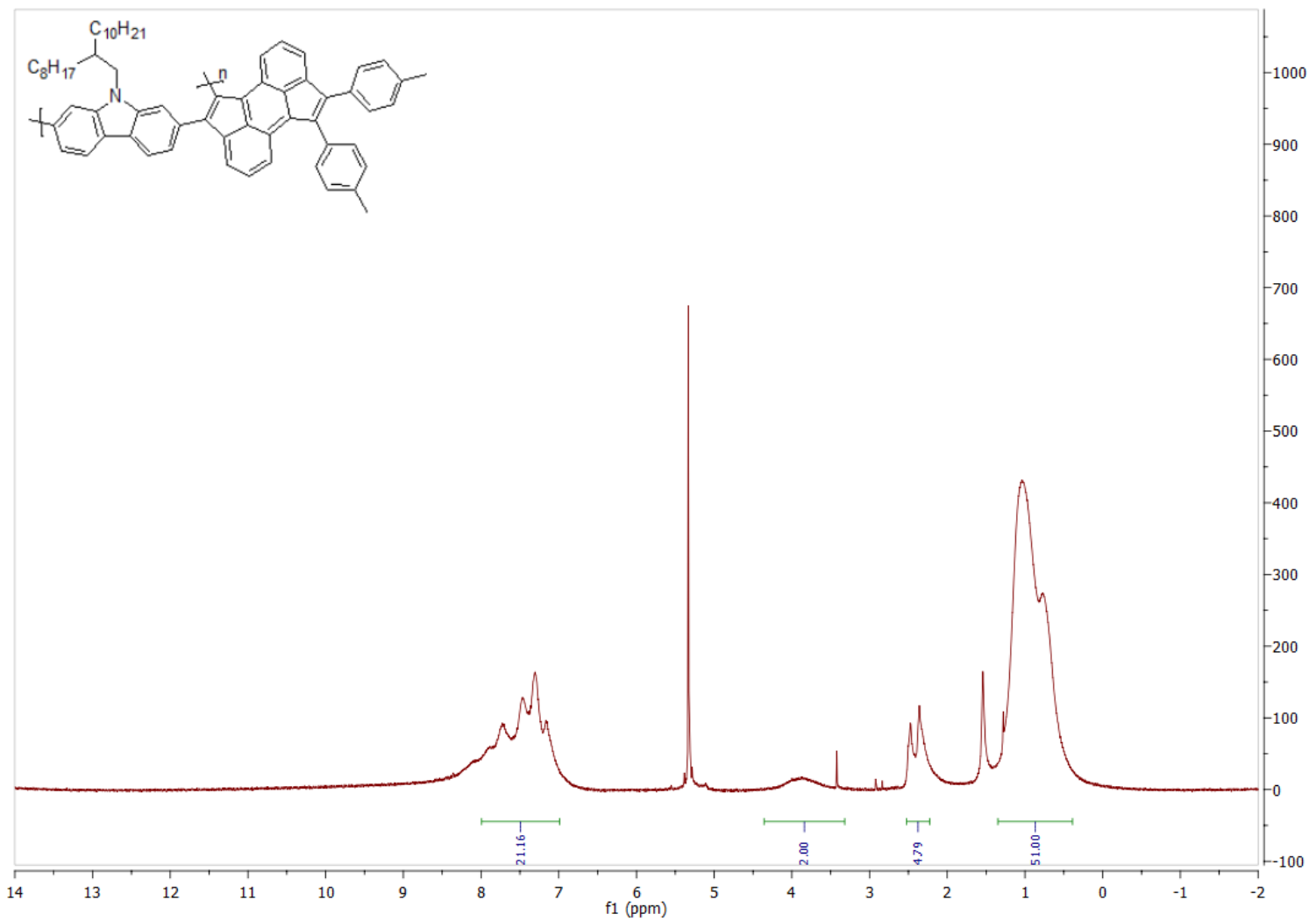




\section{Polymer 6}

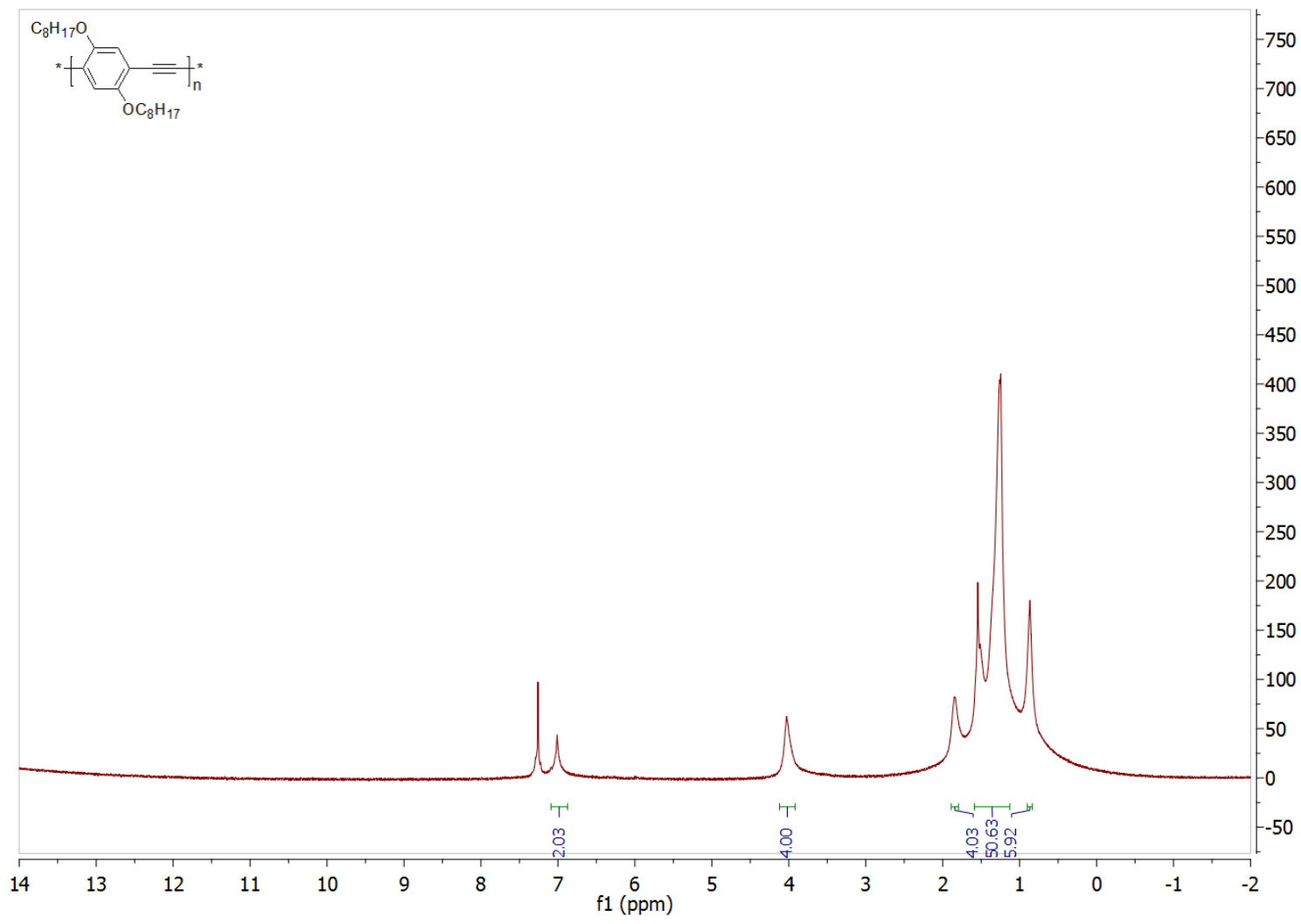




\section{Polymer 9}

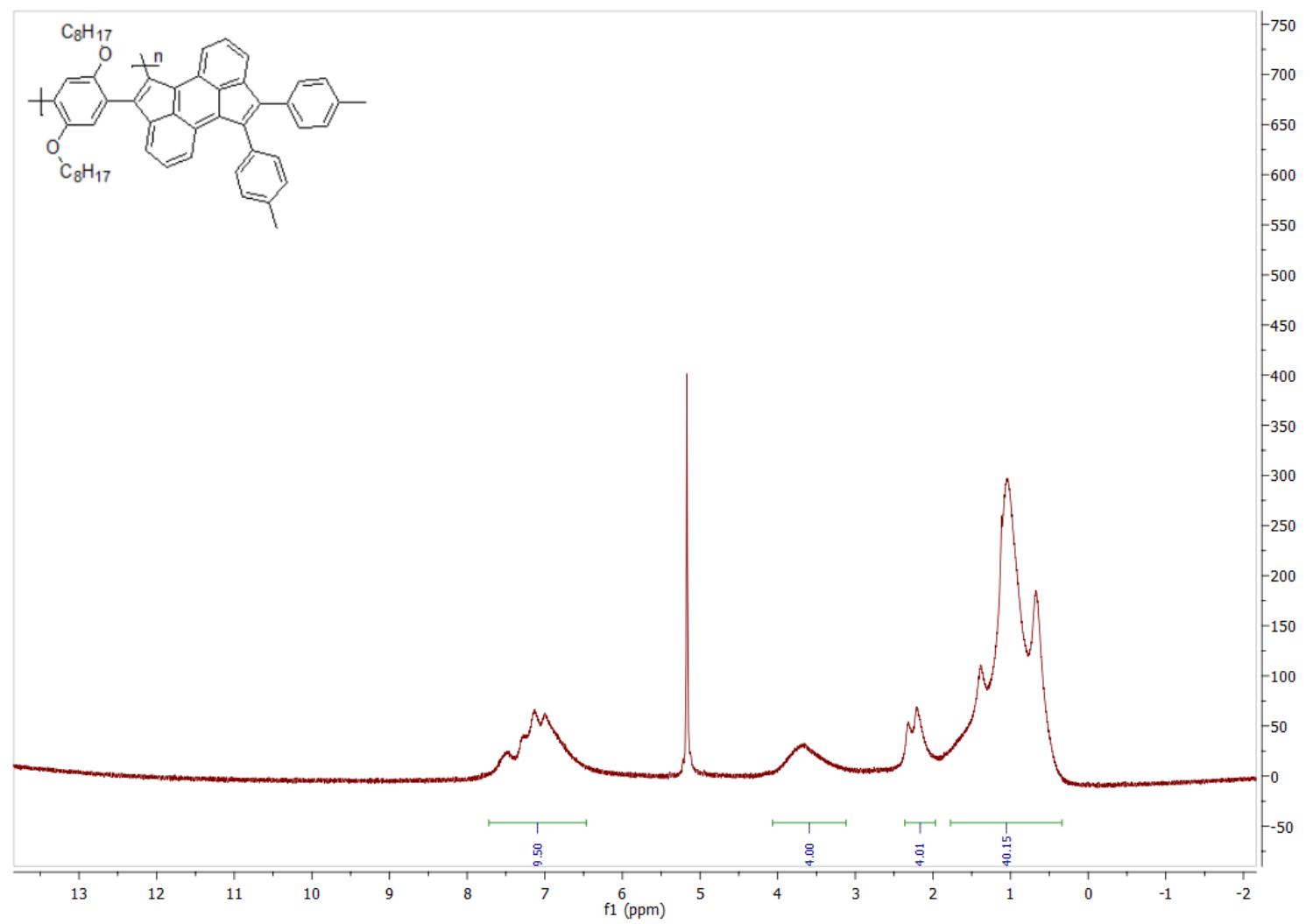




\section{References:}

(1) Mio, M. J.; Kopel, L. C.; Braun, J. B.; Gadzikwa, T. L.; Hull, K. L.; Brisbois, R. G.; Markworth, C. J.; Grieco, P. A. Org. Lett. 2002, 4 (19), 3199-3202. 